\title{
Understanding the Welfare Effects of Unemployment Insurance Policy in General Equilibrium*
}

\author{
Toshihiko Mukoyama ${ }^{\dagger}$
}

January 2010

\begin{abstract}
This paper analyzes the welfare effects of the change in unemployment insurance benefits in three general equilibrium incomplete market models. In particular, it decomposes the total effect for each individual into different factors. In all of the models that I consider, the consumers face an uninsurable unemployment risk, can save in a interest-bearing asset, and face a borrowing constraint. I find that (i) in the models that are calibrated to the U.S. economy, the welfare benefit of having access to unemployment insurance above the current U.S. level is very limited, (ii) the changes in equilibrium prices tend to create a conflict of interest between poor and rich consumers, (iii) considering the endogenous reaction of the equilibrium unemployment rate to unemployment insurance benefit is important when considering the welfare effect of the change in equilibrium prices, and (iv) an unanticipated change in unemployment insurance benefits involves implicit transfers. Details of the model matter substantially in shaping the total welfare outcome, both through the direct effect on individuals and through the general equilibrium effect.
\end{abstract}

Keywords: Welfare Effect, Unemployment Insurance, Heterogeneous Agents JEL Classifications: E24, E62, H30, J65

*I thank seminar participants at Rochester Wegmans Conference, "Recent Development in Macroeconomics" conference at Yonsei University, Federal Reserve Bank of Philadelphia, and Concordia University for comments and suggestions. All errors are mine.

${ }^{\dagger}$ University of Virginia and CIREQ, tm5hs@virginia.edu 


\section{Introduction}

Unemployment insurance (UI) allows consumers to cope with the risk of large fluctuations in income due to job losses. It also provides a method of smoothing consumption while unemployed, particularly for consumers who are constrained in borrowing. Because this type of insurance is difficult to provide through the private market, UI has long been viewed as an important government policy. There has been a large amount of research devoted to understanding the effect of government-provided UI, on both theoretical and empirical fronts. ${ }^{1}$

In the past 30 years, many papers have been written on "optimal UI policy." These papers typically consider a set of available UI policy options, and selects the "optimal" policy based on certain welfare criteria. Existing papers vary widely in terms of the environments they consider and the restrictions that they put on the available policy instruments. Some papers analyze environments with only one consumer, ${ }^{2}$ some consider environments with many heterogeneous consumers, ${ }^{3}$ and others construct a fully general equilibrium environment with production. ${ }^{4}$ Some papers consider a fully duration-dependent UI benefit, ${ }^{5}$ some only consider a constant benefit with various levels ${ }^{6}$ and others analyze a benefit that is non-constant but has restricted flexibility. ${ }^{7}$

The quantitative literature differs substantially on their recommendation of the "optimal UI benefit." It turns out that the results depend on the details of the model, and the models typically involve many elements that are affected by the change in the UI benefit, so that it is difficult to identify which details are driving the differences in the results. To learn from the models and draw lessons for the actual policy making, it does not seem productive to simply list various numbers that are obtained from different settings. Rather, it is necessary to understand how these quantitative conclusions are drawn.

This paper contributes to this understanding. Instead of calculating the optimal UI scheme, I consider the welfare effect of a simple UI reform that moves the benefit level from "low" to "high." The models that I analyze are all dynamic general equilibrium models with uninsured idiosyncratic unemployment risk. In particular, I analyze a class of models called Bewley models. ${ }^{8}$ These models assume that consumers follow a "permanent-income" behavior: in the model they cannot insure against idiosyncratic risk directly, have an access to an interestbearing asset (and thus are able to self-insure), and are subject to a borrowing constraint. One aspect of the model that I emphasize is that consumers are heterogeneous in employment statuses and asset levels at a given point in time. This makes it difficult to evaluate the

\footnotetext{
${ }^{1}$ See the footnotes below for examples of theoretical work. For empirical studies see, for example, Meyer (1990) and Gruber (1997).

${ }^{2}$ For example, Shavell and Weiss (1979), Hopenhayn and Nicolini (1997), and Shimer and Werning (2008).

${ }^{3}$ For example, Hansen and İmrohoroğlu (1992), Abdulkadiroğlu et al. (2002), and Lentz (2009).

${ }^{4}$ For example, Young (2004) and Krusell et al. (2009a).

${ }^{5}$ For example, Shavell and Weiss (1979), Hopenhayn and Nicolini (1997), and Shimer and Werning (2008).

${ }^{6}$ For example, Hansen and İmrohoroğlu (1992), Young (2004), and Krusell et al. (2009)

${ }^{7}$ For example, Abdulkadiroğlu et al. (2002).

${ }^{8}$ See Bewley (undated), Huggett (1993), and Aiyagari (1994).
} 
welfare effects of a policy change - the welfare effects for a particular consumer depends on her individual state at the time of the policy change. ${ }^{9}$ The following analysis describes the individual-level welfare effects and decomposes them into various factors.

I consider three models. The first model (called "exogenous unemployment model") is by Aiyagari (1994). The consumers face an uninsurable idiosyncratic unemployment shock, which is given exogenously. They can save in the form of capital stock. The unemployment process is exogenously modeled as shocks, and therefore UI reform has no impact on the unemployment rate. Although this feature is not realistic, this assumption simplifies the analysis and it enables us to clarify the role of an endogenous unemployment rate in the other models. The second and third models treat the unemployment rate as endogenous, utilizing different mechanisms. In both models, the unemployment rate increases in response to the increase in the UI benefit. In the second model, this is because the unemployed consumers reduce their job search effort. In the third model, the unemployment rate declines because of the reduced level of vacancy postings by the firm. I call the second model the "moral hazard model" and the third model the "search and matching model."

As can be seen in the following, different models provide very different predictions about welfare effects, even though the models share many similar components. This means that details of the model matter substantially in shaping the total welfare outcome. However, it is possible to draw general lessons by carefully decomposing the factors contributing to the welfare effects. The general lessons can be summarized as follows:

1. In the Bewley models that are calibrated to the U.S. economy, the welfare benefit of having access to further insurance beyond the current U.S. level is very limited. The pure insurance effect is significantly positive only for the consumers who are very close to the borrowing constraint. That is, the main direct benefit of unemployment insurance is the liquidity provision for the very poor.

2. The effect through prices tends to create a conflict of interest between poor and rich consumers. The direct effect of tax and the UI benefit creates a conflict between the unemployed consumers and employed consumers.

3. Considering endogenous unemployment is important when considering the effect of the change in prices. Because the labor market adjustment is much faster than the change in the aggregate asset level, the effect of the change in asset accumulation can be overweighed by the short-run effect of the change in aggregate labor.

4. An unanticipated UI benefit increase generates implicit transfers, particularly from employed consumers to unemployed consumers.

\footnotetext{
${ }^{9}$ One can imagine that this heterogeneity in welfare effects have politico-economic consequences. Pallage and Zimmermann (2001) analyze a voting equilibrium in a model similar to Hansen and İmrohoroğlu (1992) based on a steady-state welfare comparison.
} 
There are many other lessons that can be drawn from the specific models, and I will describe them in detail in the later sections.

This paper is organized as follows. Section 2 analyzes a model with an exogenous unemployment process. The model in Section 3 introduces a consumer's search effort, and highlights the effect of moral hazard. Section 4 constructs a model with search and matching frictions in the labor market. Section 5 concludes.

\section{Model 1: Exogenous unemployment model}

The first model assumes that the transitions between employment and unemployment are governed by an exogenous stochastic process. The basic structure of the model is identical to Aiyagari (1994). The asset market is incomplete - consumers are allowed to hold only one type of asset (capital). Thus, the tax-financed unemployment insurance can be beneficial to the consumers, particularly those with low level of assets.

The exogenous transition between employment and unemployment implies that the unemployment rate is unaffected by the change in the UI policy. While this is unrealistic, and I will consider two ways to depart from this assumption later, this property enables us to focus on other things that changes because of the policy change.

This model is simple, but still contains many elements that are affected by a change in the UI benefit. Consider, for example, an increase in the UI benefit. Most directly, this enables the consumer to have more income when unemployed. This provides insurance and liquidity for an unemployed consumer. All things equal, this increases all consumers' permanent incomes as well. Second, there are indirect effects of the policy change on the individual consumers. The obvious one is the change in taxes: if the individual benefit increases and the unemployment rate does not change, the government has to finance more funds by raising taxes. The other effect is the change in prices - the change in individual behavior translates into the market prices and in turn affects individual welfare. In the current model, a reduction of individual risk by a more generous UI benefit decreases precautionary savings, and therefore reduces the aggregate capital stock. This increases the interest rate and reduces the wage rate. In the following, the tax effect and the price effect are also quantitatively evaluated.

\subsection{Setup}

\subsubsection{Consumers}

Time is discrete and there is a continuum of infinitely-lived consumers with population 1. A consumer maximizes the discounted lifetime utility

$$
\mathbf{U}=E\left[\sum_{t=0}^{\infty} \beta^{t} \log \left(c_{t}\right)\right],
$$


where $\beta \in(0,1)$ is the discount factor, $c_{t}$ is the consumption at time $t$, and $E[\cdot]$ denotes the expectation at time 0 . The consumer can hold only one kind of asset, namely the capital stock. Let $a_{t}$ be the capital stock holding at time $t$. The net rental rate of the capital stock at time $t$ is $r_{t}$. The depreciation rate of the capital stock is $\delta \in(0,1)$. When employed, the consumer works $\bar{h}$ fixed hours, and is paid the wage $w_{t}$ per hour. The consumer also faces a borrowing constraint: $a_{t+1} \geq \underline{a}$ has to hold, where $\underline{a}$ is the borrowing limit. While unemployed, the consumer receives an unemployment benefit $b$. The government finances the UI through a lump-sum tax on all consumers. The government balances the budget every period, and the tax at time $t$ is denoted as $T_{t}$.

An employed consumer is separated from her job with probability $\sigma \in(0,1)$. An unemployed consumer finds a job with probability $\lambda_{w}$. In this section, $\sigma$ and $\lambda_{f}$ are given exogenously, and are unchanged by policy or individual behavior. This means that the unemployment rate converges to the value $\bar{u}=\sigma /\left(\sigma+\lambda_{w}\right)$. Throughout this section, I focus on the situation where the unemployment rate is constant at $\bar{u}$.

The Bellman equation for an employed consumer is:

$$
W_{t}\left(a_{t}\right)=\max _{c_{t}, a_{t+1}} \log \left(c_{t}\right)+\beta\left[(1-\sigma) W_{t+1}\left(a_{t+1}\right)+\sigma U_{t+1}\left(a_{t+1}\right)\right]
$$

subject to

$$
c_{t}+a_{t+1}=\left(1+r_{t}-\delta\right) a_{t}+w_{t} \bar{h}-T_{t}
$$

and

$$
a_{t+1} \geq \underline{a},
$$

where $W_{t}\left(a_{t}\right)$ is the value function for an employed consumer with asset level $a_{t}$ at time $t$ and $U_{t}\left(a_{t}\right)$ is the value function for an unemployed consumer with asset level $a_{t}$ at time $t$. The Bellman equation for an unemployed consumer is

$$
U_{t}\left(a_{t}\right)=\max _{c_{t}, a_{t+1}} \log \left(c_{t}\right)+\beta\left[\lambda_{w} W_{t+1}\left(a_{t+1}\right)+\left(1-\lambda_{w}\right) U_{t+1}\left(a_{t+1}\right)\right]
$$

subject to

$$
c_{t}+a_{t+1}=\left(1+r_{t}-\delta\right) a_{t}+b-T_{t}
$$

and

$$
a_{t+1} \geq \underline{a} .
$$

\subsubsection{Firms}

There is a continuum (population 1) of competitive firms, each using an identical technology. A firm operates with constant returns to scale technology

$$
y_{t}=k_{t}^{\alpha} l_{t}^{1-\alpha}
$$

where $\alpha \in(0,1), y_{t}$ is the output at time $t, k_{t}$ is the capital input at time $t$, and $l_{t}$ is the labor input at time $t$. Since the firms are identical and their population is 1 , I consider the 
representative firm with $y_{t}=Y_{t}, k_{t}=K_{t}$, and $l_{t}=L_{t}$, where $Y_{t}$ is the aggregate output at time $t, K_{t}$ is the aggregate capital input at time $t$, and $L_{t}$ is the aggregate labor input at time $t$.

\subsubsection{Government}

The government collects taxes and provides the unemployment insurance benefit. It balances the budget in each period:

$$
T_{t}=u_{t} b
$$

where $u_{t}$ is the unemployment rate at time $t$. In the current model, $u_{t}$ is constant at $\bar{u}$, therefore $T_{t}$ only depends on the level of $b$.

\subsubsection{Equilibrium}

The competitive equilibrium of the model can be defined in a standard manner, and thus the formal definition is omitted. In the asset market equilibrium, the total amount of capital input, $K_{t}$, is equal to the total asset holdings of all consumers:

$$
K_{t}=\int a_{t}^{i} d i
$$

where $i$ indexes consumers. In the labor market equilibrium, the total labor input, $L_{t}$, is equal to the labor supplied by employed consumers:

$$
L_{t}=\left(1-u_{t}\right) \bar{h}
$$

Thus, when $u_{t}$ is constant, $L_{t}$ is also constant.

From the firm's first order condition, the interest rate and the wage are solved as

$$
r_{t}=\alpha\left(\frac{K_{t}}{L_{t}}\right)^{\alpha-1}
$$

and

$$
w_{t}=(1-\alpha)\left(\frac{K_{t}}{L_{t}}\right)^{\alpha} .
$$

Note that $r_{t}$ is decreasing in $K_{t} / L_{t}$ (therefore in $K_{t}$ when $L_{t}$ is constant) and $w_{t}$ is increasing in $K_{t} / L_{t}$.

\subsection{Results}

The model calibration follows the standard practice. One period corresponds to one month. The discount factor $\beta=0.9967$, which makes the net annual rate of asset return approximately $4 \%$. The value of $\bar{h}$ is set at $1 / 3$. The production function parameter $\alpha$ corresponds to the capital share, and it is set at $1 / 3$. The depreciation rate is $\delta=0.0067$, which corresponds to 


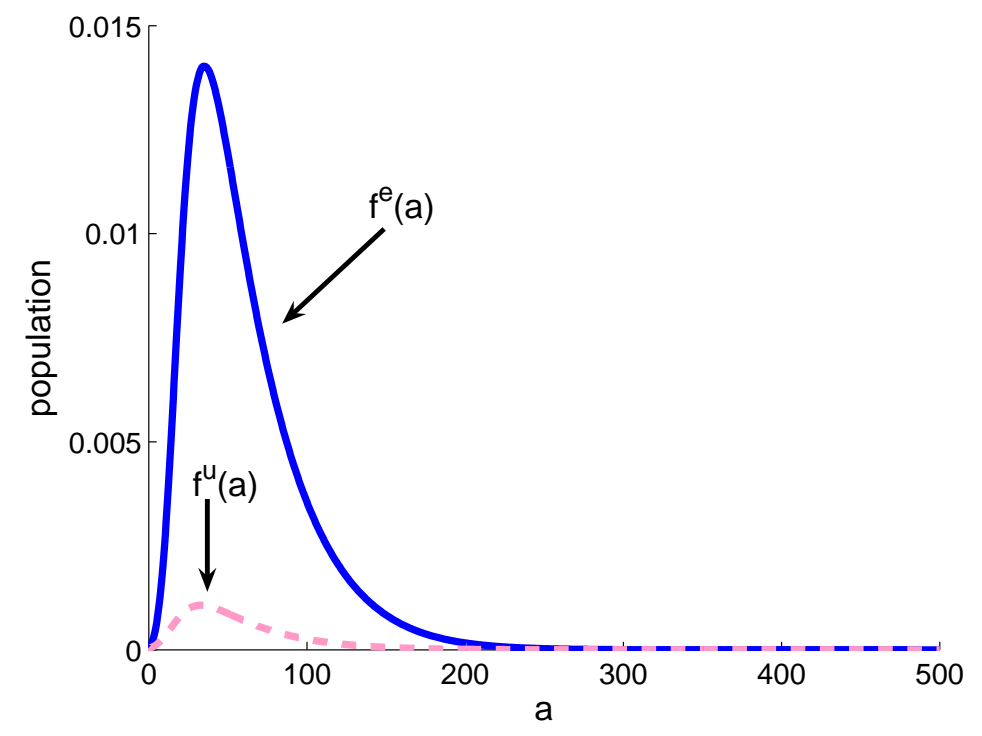

Figure 1: Wealth distribution: stationary measure of employed consumers $\left(f^{e}(a)\right)$ and unemployed consumers $\left(f^{u}(a)\right)$

an annual value of $8 \%$, leading to an equilibrium investment-output ratio of approximately 0.2 . The job-finding probability, $\lambda_{f}$, is 0.26 , which implies that the average duration of unemployment is about 15 weeks. This is in line with the U.S. experience since the 1980s (Mukoyama and Şahin (2009)). The separation rate $\sigma$ is set at 0.02 so that the steady-state unemployment rate $\bar{u}$ becomes $7.1 \%$. The value of $b$ is set at 0.27 . This leads to a net replacement rate of about $20 \%$, which is in line with the U.S. benefit level. ${ }^{10}$ The borrowing limit $\underline{a}$ is zero.

Figure 1 shows the stationary measures (populations) of employed consumers (denoted by $f^{e}(a)$ ) and unemployed consumers (denoted by $f^{u}(a)$ ) in terms of wealth. As is well known, the Aiyagari (1994) model with unemployment risk only cannot replicate the dispersed wealth distribution that is seen in the data (see, for example, Krusell and Smith (1998)). ${ }^{11}$ Appendix A considers a modified model that is similar to Krusell and Smith (1998) and Krusell et al. (2009). The model in Appendix A successfully matches the wealth distribution in the data by introducing a heterogeneity in the discount factor $\beta$. It turns out that the results of the welfare analysis in Appendix A are similar to the ones in this section, and for simplicity I maintain the current structure of the model throughout the paper.

\footnotetext{
${ }^{10}$ See Martin (1996, Table2). In reality, the replacement rates typically vary with the unemployment duration. The $20 \%$ benefit level is lower than the "first year benefit level" in the U.S., and higher than the "after the second year benefit level" in the U.S.

${ }^{11}$ For example, the Gini coefficient of wealth is 0.80 in the U.S. data (Budría Rodríguez et al. (2002, Table 1)) while it is 0.32 in the current model.
} 




Figure 2: Transition path of aggregate capital-labor ratio $\left(K_{t} / L_{t}\right)$ after the policy change

\subsubsection{Full experiment}

The experiment throughout this paper makes the UI benefit more generous. In particular, I target the European level (such as France and Denmark) by setting the benefit level at $\tilde{b}=0.90$, which leads to the net replacement rate of about $69 \%$ in the new steady state. At time 0 , there is an unexpected increase in the benefit from $b$ to $\tilde{b}$. At the same time, the tax $T$ increases to balance the budget. Denote the new tax as $\tilde{T}$. I assume that, before time 0 , the economy is in the steady state (with the old benefit level in place). Because the unemployment process is exogenous, the unemployment rate is unchanged at $\bar{u}$.

After the policy change, consumers change their consumption-saving decisions. Because they face less risk, precautionary savings are reduced. As a result, aggregate capital experiences a transition. Figure 2 plots the transition path of $K_{t} / L_{t}$. Because $L_{t}$ is constant, this transition is entirely due to the decline in $K_{t}$. This decline in $K_{t} / L_{t}$ implies that $r_{t}$ increases over time and $w_{t}$ decreases over time.

The welfare calculation takes the transition into account. The welfare criterion used in this paper follows Lucas (1987). I calculate $\mu$ that satisfies

$$
E\left[\sum_{t=0}^{\infty} \beta^{t} \log \left((1+\mu) c_{t}^{o}\right)\right]=E\left[\sum_{t=0}^{\infty} \beta^{t} \log \left(c_{t}^{n}\right)\right],
$$

where $c_{t}^{o}$ is consumption at time $t$ under the original policy (" $o$ " for "original") and $c_{t}^{n}$ is consumption at time $t$ under the new policy (" $n$ " for "new"). Note that the $\mu$ s are different for individuals with different asset levels and employment status at time 0 , and thus I will 


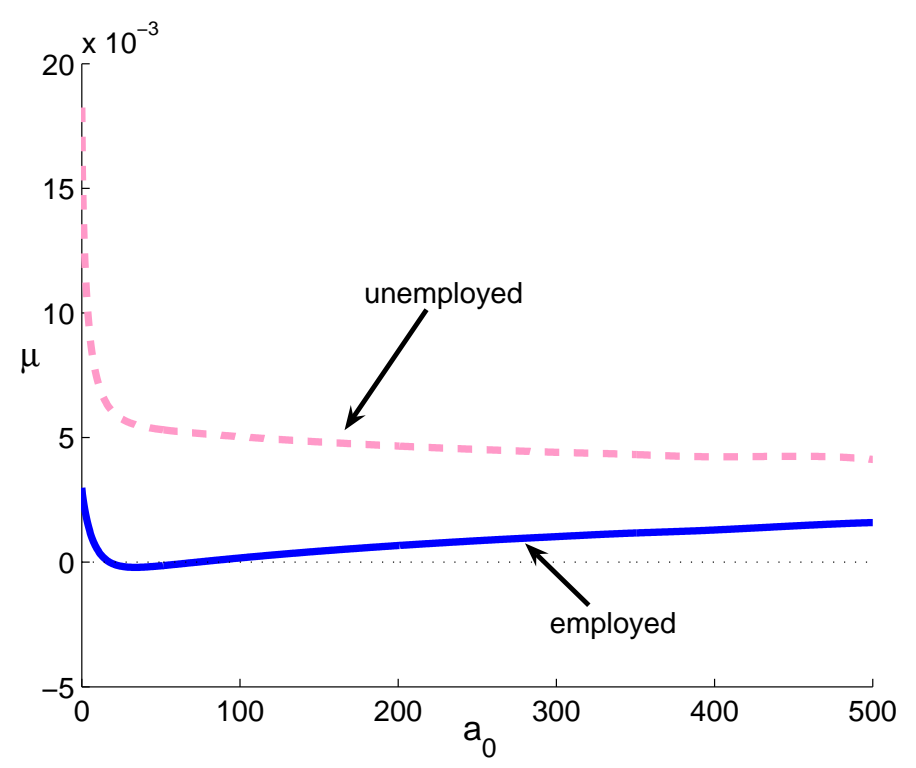

Figure 3: Welfare effects of the policy change

calculate $\mu$ for each consumer. If $\mu>0$, the consumer enjoys a welfare gain from the policy change, and if $\mu<0$ the consumer experiences a welfare loss due to the policy change.

Figure 3 plots the welfare effects of the policy effect, $\mu$, for each individual. The welfare effect differs across consumers depending on their employment status and the asset holdings at time 0 . The average value of $\mu$ is $0.00037 .{ }^{12} 33 \%$ of employed consumers and all of the unemployed consumers experience $\mu>0$. There is substantial heterogeneity. The highest welfare gain is experienced by a consumer who is borrowing-constrained $\left(a_{0}=\underline{a}\right)$ and unemployed at time 0 .

\subsubsection{Decomposition 1: Price effect}

There are many factors affecting the welfare effects in Figure 3. In the following, I will decompose the total welfare effects into each factor by "turning off" all of the effects other than one particular effect that I focus on.

First, I examine the price effect. As is argued above, a decline in $K_{t}$ due to a drop in precautionary savings increases $r_{t}$ and decreases $w_{t}$. Here, the experiment is: what is the welfare effect for each individual, if $r_{t}$ and $w_{t}$ evolve as in the experiment in Section 2.2.1, while at the same time everything else (in particular $b$ and $T$ ) is unchanged?

Figure 4 plots the results. Naturally, a consumer with low $a_{0}$ suffers from a welfare loss, because their main source of income is the wage earnings. In contrast, a consumer with a high $a_{0}$ enjoys a welfare gain because $r_{t}$ increases. ${ }^{13}$

\footnotetext{
${ }^{12}$ See Mukoyama (2010) for a caveat of using the average value of $\mu$ as the aggregate welfare criterion.

${ }^{13}$ Similar effects from the price changes are documented by Krusell et al. (2009b) and Mukoyama and Şahin
} 


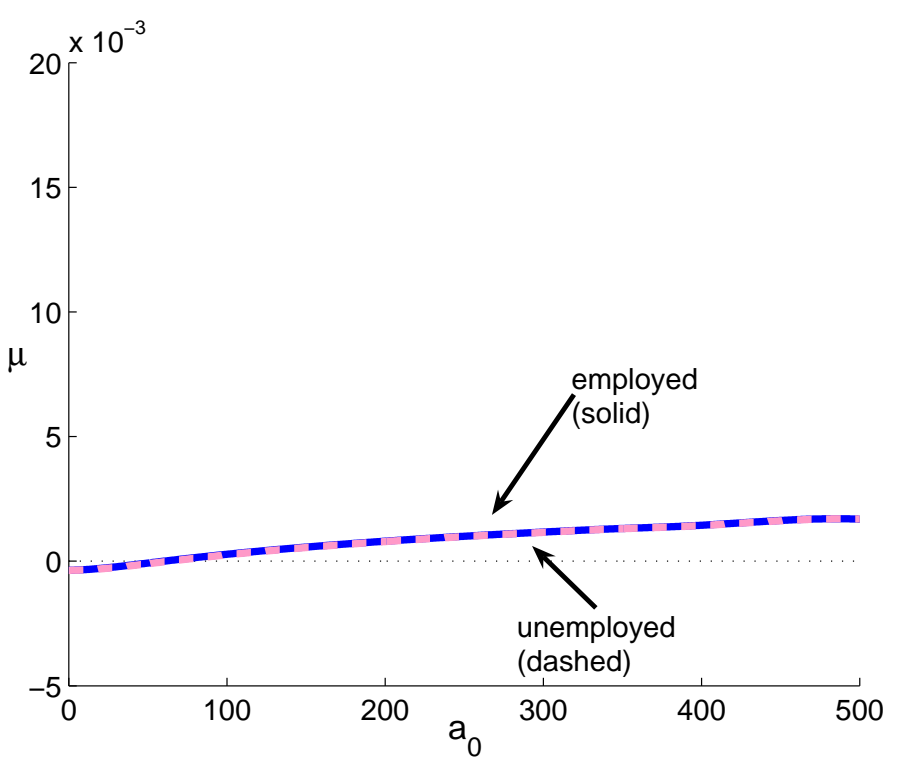

Figure 4: Welfare effects of the policy change: price effect

The effects on employed consumers and on unemployed consumers are almost identicalin the graph, the dashed line (for unemployed consumers) and the solid line (for employed consumers) almost overlap. This is somewhat surprising since one might expect that the wage effect can be different: an employed consumer receives the wage immediately while an unemployed consumer will have no wage income until she finds a job. Two factors contribute to make the price effects similar between consumers with different employment status. First, the changes in prices are much slower than the changes in the individual's employment status. As can be seen in Figure 2, it takes about 70 periods to complete half of the $K_{t}$ transition (note that $L_{t}$ is constant). In contrast, an unemployed consumer finds a job in less than 4 periods on average. Second, an employed consumer tends to increase her asset level in near future (and a higher asset level means a higher share of asset income), while an unemployed consumer tends to decrease her asset level (which means a lower share of asset income). The immediate impact of the change in wages is (partly) canceled out by the effect through these future asset changes.

Quantitatively, the price effect is very small (note that Figure 4 is drawn in the same scale as Figure 3). This reflects the fact that the total amount of precautionary savings is relatively small, so its reduction does not have a large impact on prices.

(2006) in the context of business cycle stabilization. 


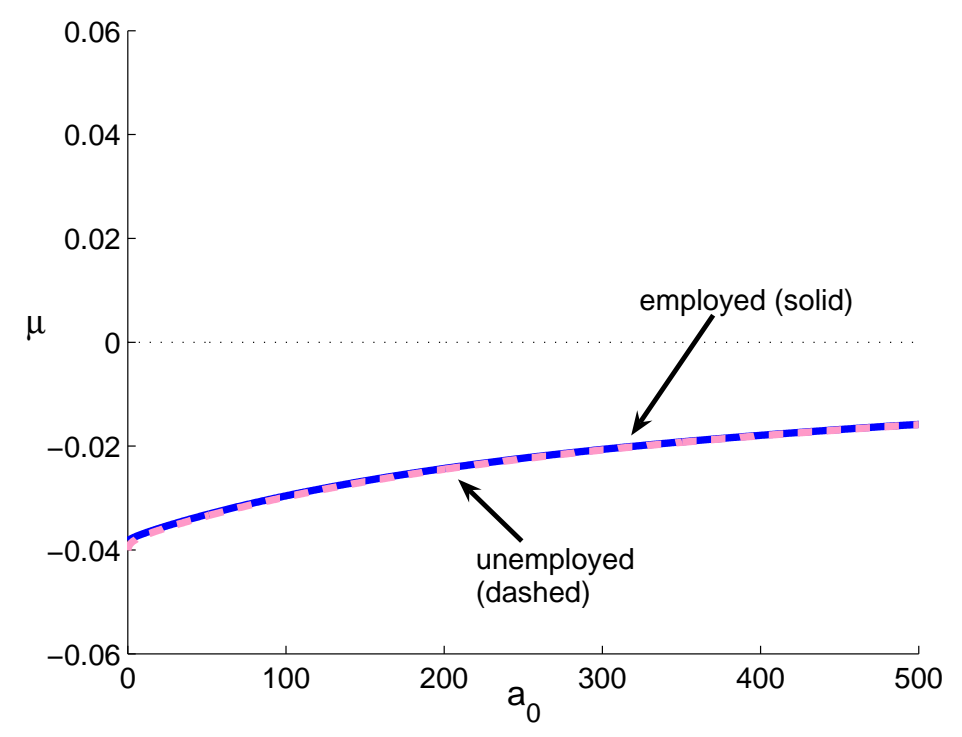

Figure 5: Welfare effects of the policy change: tax effect

\subsubsection{Decomposition 2: Tax effect}

The second decomposition experiment is: what is the welfare effect if the tax $T_{t}$ changes to $\tilde{T}_{t}$ while everything else (including prices and the benefit $b_{t}$ ) remains the same? This measures the pure effect of the tax increase.

Figure 5 shows this effect. The tax effect is quantitatively very large (note that the scale has changed). It is natural because a higher benefit is not taken into account. It also can be seen that the tax effect is similar between employed consumers and unemployed consumers. This is because the tax is lump-sum and does not depend on employment status.

\subsubsection{Decomposition 3: Benefit only}

The "opposite" of the previous experiment is the one where the benefit $b$ changes to $\tilde{b}$ but everything else (including prices and the tax $T_{t}$ ) remains the same. Figure 6 plots the welfare effects from this experiment. As expected, the effect is positive for everyone, and the quantitative significance is similar to the tax effect (Figure 6 is drawn with the same scale as Figure $5)$. Thus, to a large extent, these two effects cancel each other out.

One notable difference from Figure 5 is that the unemployed consumer experiences a quantitatively larger effect. Thus, it can be expected that, when canceled out, an unemployed consumer receives a relatively more positive effect than an employed consumer. 


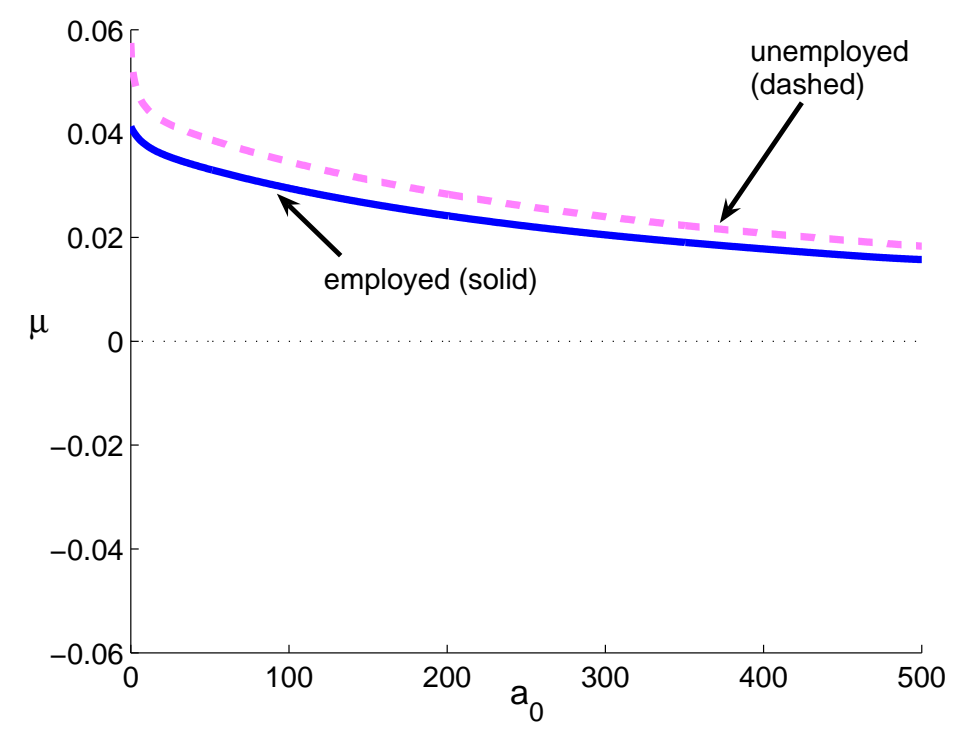

Figure 6: Welfare effects of the policy change: benefit effect

\subsubsection{Decomposition 4: Tax and benefit combined}

To see how the tax effect and the benefit effect cancel out, here I impose both the new tax level $\tilde{T}_{t}$ and the new benefit level $\tilde{b}$. As can be seen in Figure 7, the combined effect is larger for unemployed consumers. The effect is positive for all unemployed consumers but employed consumers with high asset levels experience a welfare loss - only $28 \%$ of the employed consumers gain. This is because unemployed consumers receive a higher benefit immediately (and are likely to receive it for some time), while an employed consumer's income won't change until she becomes unemployed. This difference constitutes a large part of the difference of the welfare effects in Figure 3. Because employed consumers pay the same amount of tax as unemployed consumers while the benefit is skewed more heavily toward the unemployed consumers, this policy creates an implicit wealth transfer from employed consumers to unemployed consumers. More generally, an unanticipated policy change creates this type of implicit transfer, ${ }^{14}$ and this can create a disagreement across agents in deciding whether to implement a particular policy.

\subsubsection{Decomposition 5: Pure insurance effect}

The direct effect of the UI benefit change in Figure 6, even after adjusting for the increase in tax as in Figure 7, does not provide direct information about how the UI is performing in its capacity as insurance, because it also includes the implicit transfer. In order to evaluate the

\footnotetext{
${ }^{14}$ For example, the analysis by Doepke and Schneider (2006) highlights this type of implicit transfer. See also Mukoyama (2009).
} 


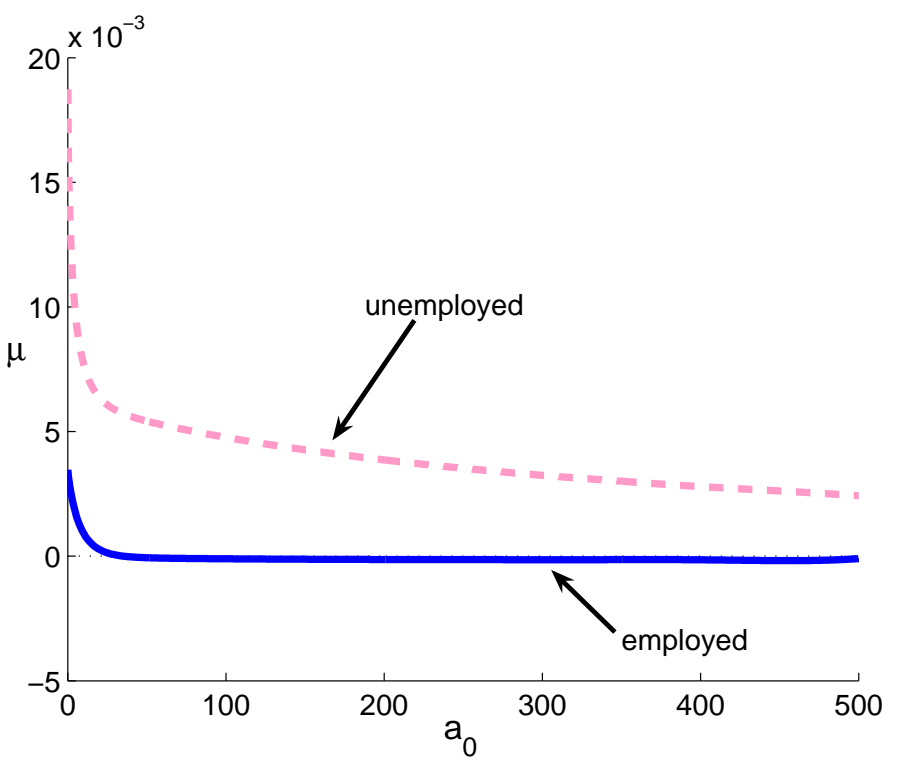

Figure 7: Welfare effects of the policy change: tax effect and benefit effect together

pure insurance effect, the transfer effect has to be neutralized.

To this end, here I implement a UI reform that is "actuarially fair" at the individual level. ${ }^{15}$ In particular, each consumer pays an insurance premium every period so that the present value of this premium is equal to the expected present value of the benefit received, given the initial employment state. I apply this premium to the additional UI benefit $\tilde{b}-b$. The amount $b$ continues to be financed by the lump-sum tax as before.

In particular, I calculate the expected present value (evaluated at time $t$ ) of the extra benefit for a consumer who is unemployed at $t, Z_{t}^{u}$, and for a consumer who is employed at $t, Z_{t}^{e}$, as the following:

$$
Z_{t}^{u}=\tilde{b}-b+\frac{1}{1+r_{t+1}-\delta}\left[\lambda_{w} Z_{t+1}^{e}+\left(1-\lambda_{w}\right) Z_{t+1}^{u}\right]
$$

and

$$
Z_{t}^{e}=\frac{1}{1+r_{t+1}-\delta}\left[(1-\sigma) Z_{t+1}^{e}+\sigma Z_{t+1}^{u}\right]
$$

Then, the time- $t$ insurance premium for a consumer who is unemployed at time $0, \tau_{t}^{u}$, and for a consumer who is employed at time $0, \tau_{t}^{e}$, are calculated as: ${ }^{16}$

$$
\tau_{t}^{u}=\frac{r_{t}-\delta}{1+r_{t}-\delta} Z_{0}^{u}
$$

\footnotetext{
${ }^{15}$ Lentz (2009) calculates an optimal UI benefit in a partial equilibrium model with a similar type of benefit financing.

${ }^{16}$ The fact that the present value of $\tau_{t}^{i}, \sum_{t=0}^{\infty} \tau_{t}^{i} / R_{t}$ where $R_{t}=\prod_{j=0}^{t}\left(1+r_{j}-\delta\right)$, is equal to $Z_{0}^{i}$ can be checked by applying the fact that $1=\left(r_{t}-\delta\right) /\left(1+r_{t}-\delta\right)+1 /\left(1+r_{t}-\delta\right)$ repeatedly.
} 


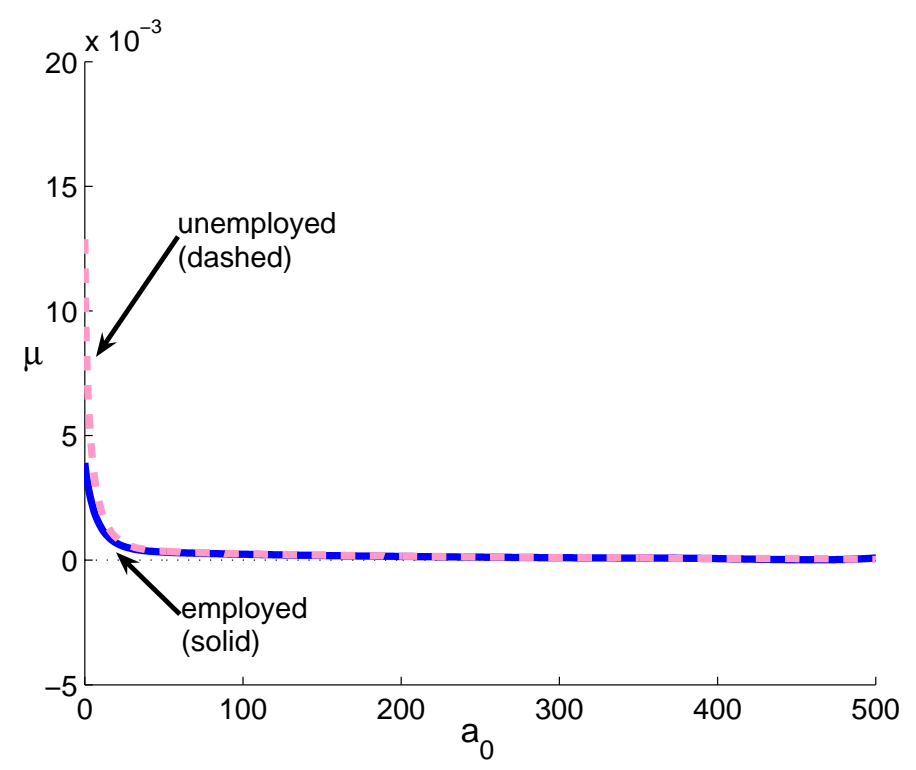

Figure 8: Welfare effects of the policy change: pure insurance effect

and

$$
\tau_{t}^{e}=\frac{r_{t}-\delta}{1+r_{t}-\delta} Z_{0}^{e}
$$

In the current experiment, $r_{t}$ is constant so the insurance premium is also constant over time.

The experiment here is to change the benefit from $b$ to $\tilde{b}$, make the consumers pay $\tau_{t}^{i}$ depending on the time- 0 employment status $i \in\{e, u\}$, and everything else (including the prices and the $\operatorname{tax} T_{t}$ ) remains the same. $\tau_{t}^{i}$ can also be considered as the "personalized tax" imposed on each individuals for the extra benefit. Figure 8 plots the welfare effects. The pure insurance effect is positive for everyone. However, for most of the consumers, the welfare effect is very close to zero. The opportunity to better insure against shocks brings significant welfare benefits only to the consumers who are close to the borrowing constraint.

\section{Model 2: Moral hazard model}

In this section and the next, I extend the model so that the unemployment rate reacts to the UI benefit. This section presents a model where an unemployed consumer makes a job search effort which is not observable to the government. Thus, the government cannot condition the UI benefit level on the level of search effort, and the problem of moral hazard arises.

This type of model is very popularly used for the analysis of UI in the literature. Examples include Shavell and Weiss (1979), Andolfatto and Gomme (1996), Wang and Williamson (1996, 2002), Hopenhayn and Nicolini (1997), Young (2004), and Lentz (2009). This section closely follows the formulation of Young (2004). 


\subsection{Setup}

The setup is similar to Section 2. The only difference is that the probability of finding a job $\lambda_{w}$ is a function of the search effort $e_{t}$ by the unemployed consumer. The consumer has to incur a utility cost $e_{t}^{\omega}$ with $\omega>1$ when she makes a search effort. The level of $e_{t} \geq 0$ is chosen by the consumer. The utility function of the consumer is modified to

$$
\mathbf{U}=E\left[\sum_{t=0}^{\infty} \beta^{t} \log \left(c_{t}\right)-e_{t}^{\omega}\right] .
$$

The consumer chooses $e_{t}=0$ when employed, since there is no benefit from making an effort while employed. The probability of finding a job, $\lambda_{w}\left(e_{t}\right)$, is

$$
\lambda_{w}\left(e_{t}\right)=1-\exp \left(-\phi e_{t}\right)
$$

where $\phi>0$. Clearly, the optimal choice of $e_{t}$ varies across different $a_{t}$.

\subsection{Results}

The calibrated parameters are the same as the Section 2, except for the job finding process. Following Wang and Williamson (2002) and Young (2004), I fix the value of $\omega$ to $2 .{ }^{17}$ The value of $\phi$ is pinned down (at $\phi=0.437$ ) by requiring that the steady-state unemployment rate is $7.1 \%$.

Figure 9 plots the job-finding probabilities $\lambda_{w}(e)$ for different values of $a$, when the economy is in the steady state with $b=0.27$ and $e$ is chosen by the individual optimization of the consumer. The job-finding probability is lower when $a$ is higher, which means that wealthier consumers spend longer periods of time being unemployed.

The benchmark steady state features the invariant distribution of the asset across consumers. The asset distribution looks very similar to the previous section and therefore it is not plotted here.

\subsubsection{Full experiment}

The experiment here is the same as in Section 2.2.1: increase the value of the UI benefit to $\tilde{b}=0.90$ at time 0 , while changing the tax $\tilde{T}_{t}$ so that the budget balances in every period. In contrast to Section 2.2.1, the unemployment rate changes over time since the job search effort $e_{t}$ changes after the UI benefit changes, and this leads to the change in the job-finding probability $\lambda_{w}\left(e_{t}\right)$. Because the unemployment rate experiences a transition, $\tilde{T}_{t}=u_{t} \tilde{b}$ also changes over time. Similar to Section 2.2.1, there is another effect (in addition to the change in labor input) that causes the capital stock to change, which is the decline in the precautionary savings. For a given $r_{t}=\alpha\left(K_{t} / L_{t}\right)^{\alpha-1}$ the amount of saving declines, and thus $r_{t}$ has to be higher $\left(K_{t} / L_{t}\right.$ has to be lower) in the new steady-state equilibrium.

\footnotetext{
${ }^{17}$ The value of $\omega$ affects both the response of the unemployment rate to the change in UI benefit and the overall welfare effects. Appendix B summarizes the results for the case of $\omega=8$.
} 


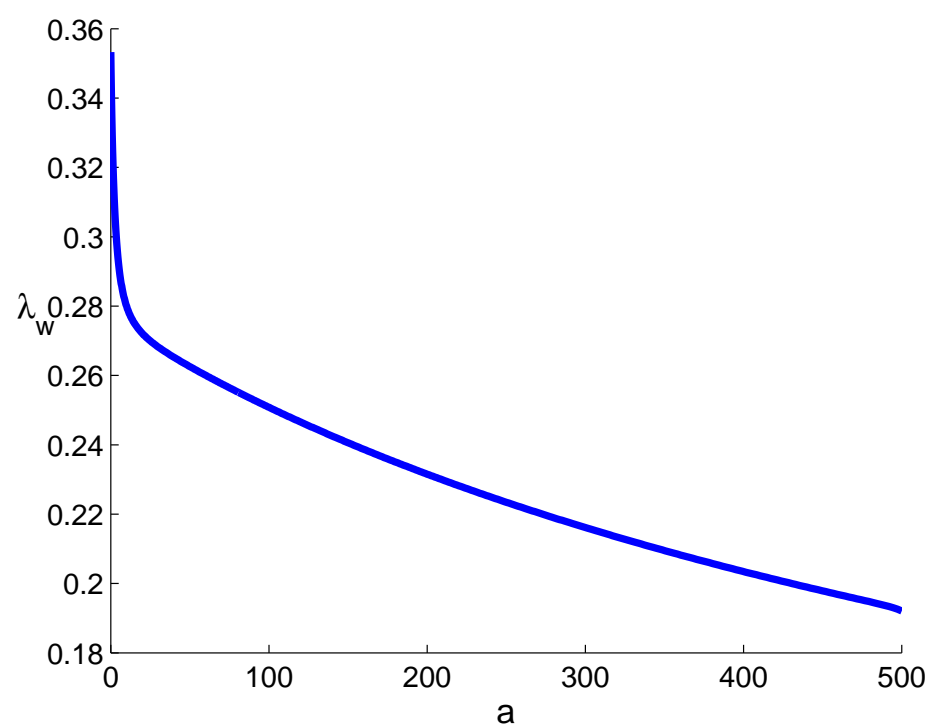

Figure 9: Job-finding probabilities when $b=0.27$

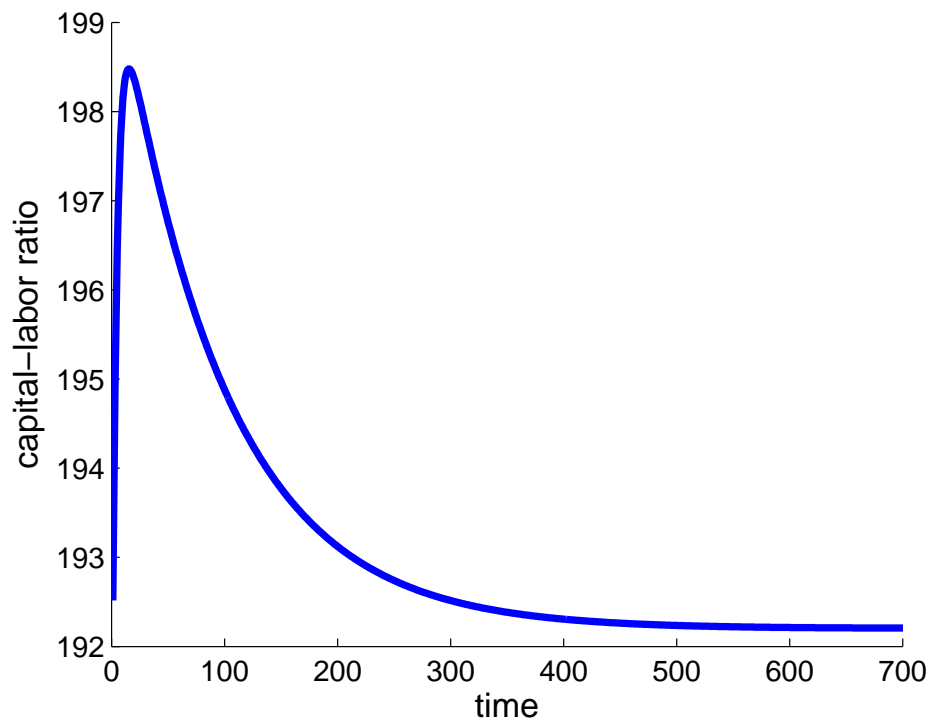

Figure 10: Transition path of aggregate capital-labor ratio $\left(K_{t} / L_{t}\right)$ after the policy change 


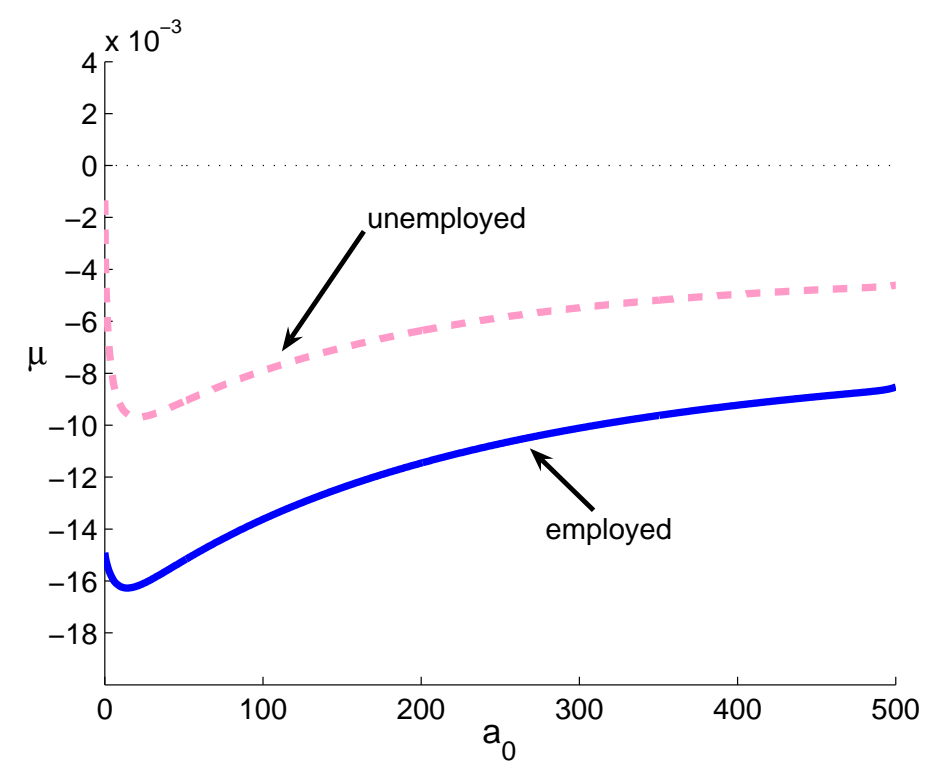

Figure 11: Welfare effects of the policy change

Figure 10 presents the time path of $K_{t} / L_{t}$ during the transition. This is strikingly different than the exogenous unemployment case (Figure 2). In particular, the transition path is nonmonotonic. $K_{t} / L_{t}$ initially goes up very rapidly, and gradually falls down to a new steady-state level which is lower than the time- 0 level of the capital-labor ratio. The reason for the nonmonotonicity is that the rates of change in $K_{t}$ and $L_{t}$ are very different: $L_{t}$ falls much more quickly than $K_{t}$ does. The unemployment rate quickly converges to its new steady-state value $(10.3 \%)$.

Figure 11 plots the welfare effects. Everyone in the economy suffers from a welfare loss. ${ }^{18}$ In the following I investigate the factors that contribute to this result.

\subsubsection{Decomposition 1: Price effect}

The experiment in this section is the same as in Section 2.2.2. The paths of $r_{t}$ and $w_{t}$ are given as the ones in Section 3.2.1 and everything else (including the benefit $b$ and the tax $T_{t}$ ) remains the same as in the benchmark steady-state.

Figure 12 plots the welfare effects. In contrast to Section 2.2.2, a wealthier consumer loses from the price change. This can be understood by comparing Figure 2 and Figure 10. Although $K_{t} / L_{t}$ falls in the long run in both figures, the transitions are dramatically different. In Figure 2 the transition is monotonic, while in Figure $10 K_{t} / L_{t}$ goes up significantly in the beginning. This effect of the initial transition phase dominates - the consumers experience a long period

\footnotetext{
${ }^{18}$ With a similar model, Young (2004) argues that welfare gains are achieved by almost everyone when the current U.S. level of UI benefits is reduced to zero.
} 


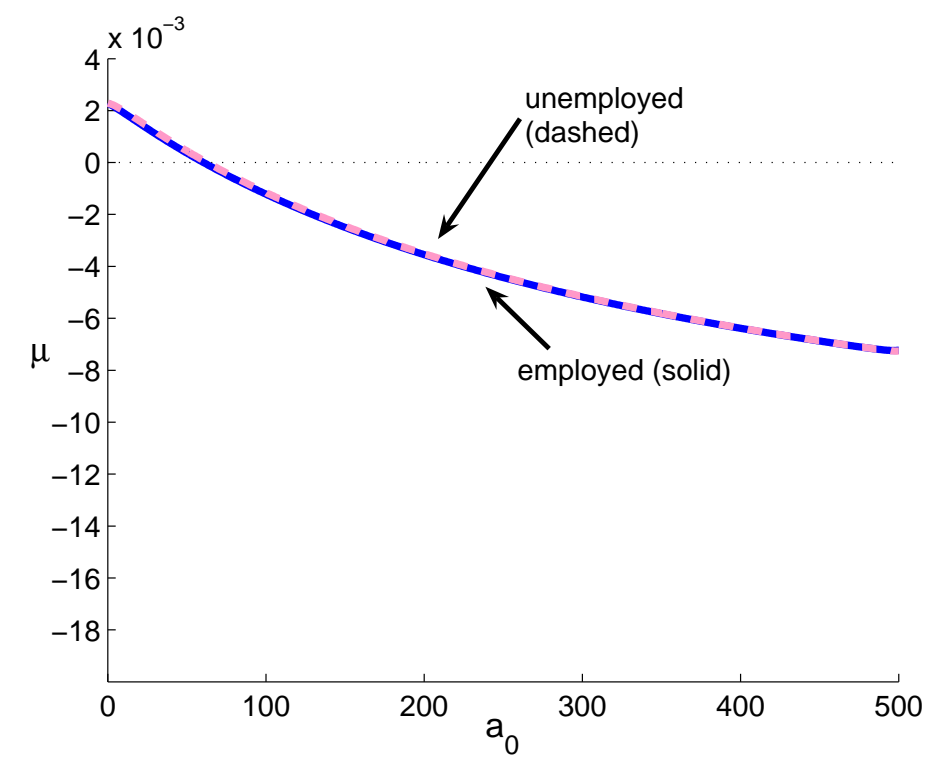

Figure 12: Welfare effects of the policy change: price effect

of high $w_{t}$ and low $r_{t}$. Because the adjustment in the labor market is much faster than the adjustment of total saving, the results of the price effect are the reverse of the exogenous unemployment case.

\subsubsection{Decomposition 2: Tax effect}

The experiment here corresponds to Section 2.2.3. Only the tax is changed (from $T_{t}$ to $\tilde{T}_{t}$ for all $t$ ). Figure 13 plots the result. As in Section 2.2.3, there is a large negative effect on everyone. By a similar logic to Section 2.2.3, the tax effect is similar for both employed and unemployed consumers.

\subsubsection{Decomposition 3: Benefit only}

This experiment is similar to Section 2.2.4. I give the consumers the new value of benefit, $\tilde{b}=0.90$, instead of $b$. Because the tax is the same, all of the consumers receive a positive benefit. However, in contrast to the tax experiment, the unemployed consumers gain more than the employed consumers.

\subsubsection{Decomposition 4: Tax and benefit combined}

As in the model of Section 2, large parts of the tax effect and the benefit effect cancel each other out. However, once both effects are put in together (that is, impose benefit $\tilde{b}$ and $\operatorname{tax} \tilde{T}_{t}$ on consumers), the outcome is very different than in Section 2.2.5. 


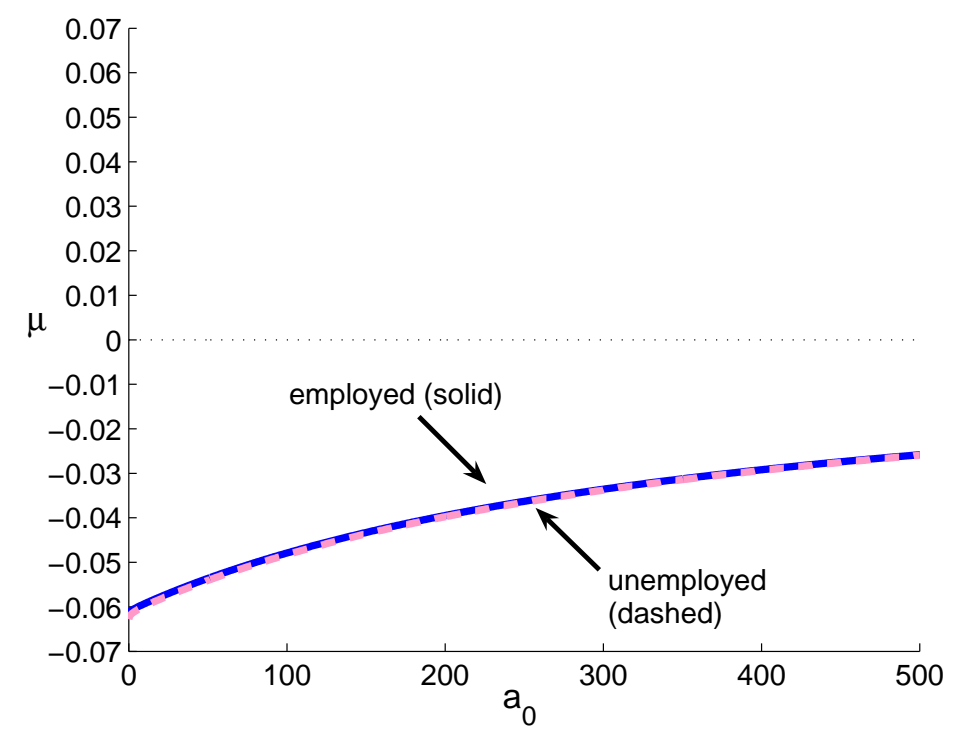

Figure 13: Welfare effects of the policy change: tax effect

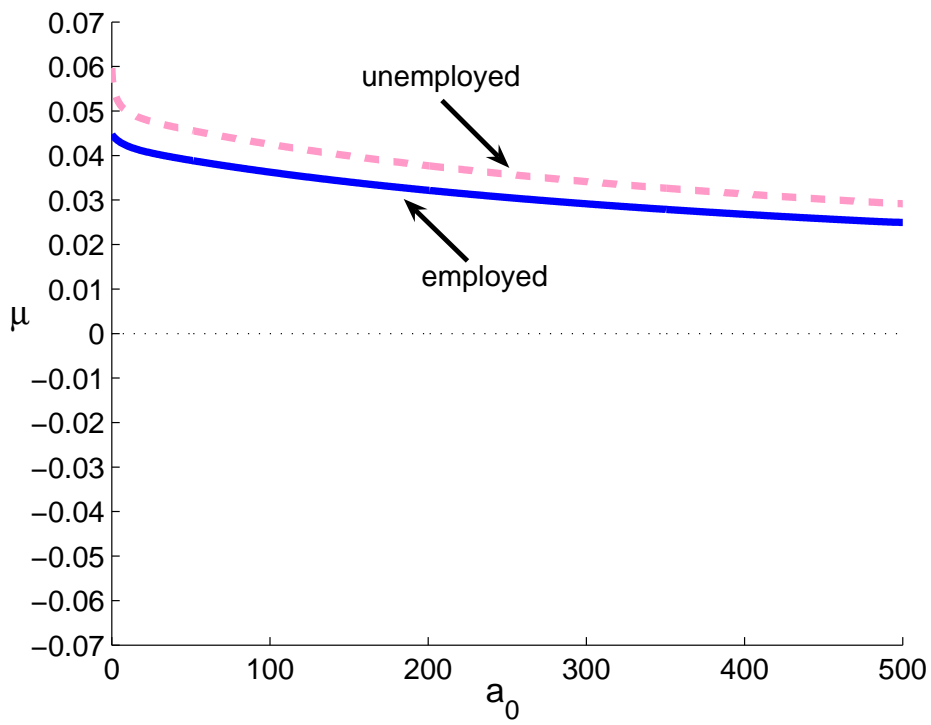

Figure 14: Welfare effects of the policy change: benefit effect 


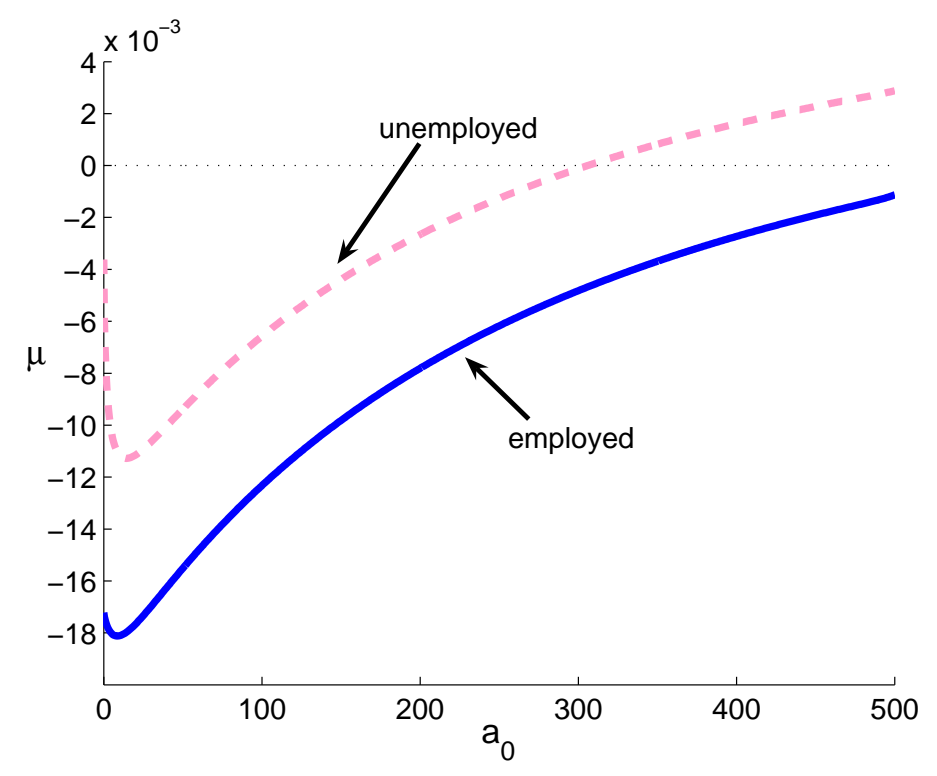

Figure 15: Welfare effects of the policy change: tax effect and benefit effect together

The welfare effects are plotted in Figure 15. In contrast to Figure 7, all of the low-asset consumers - even the unemployed ones - now experience a welfare loss. This is because wealth influences the expected present value of the benefit that one receives. In Figure 9, the jobfinding probability is decreasing in wealth. This means that a wealthy consumer spends more time being unemployed - and therefore benefits more from the extra UI benefit. Because the tax burden is the same for everyone, a poor consumer experiences a welfare loss. In other words, there is an implicit transfer from poor consumers to rich consumers. One common feature as in Figure 7 is that unemployed consumers gain more than employed consumers. As in Section 2.2.5, this reflects an implicit transfer from unemployed consumers to employed consumers.

\subsubsection{Decomposition 5: Pure insurance effect}

Here I conduct an experiment similar to Section 2.2.6: I allow the consumers to have access to actuarially fair (additional) insurance, keeping the environment unchanged. Here, the difference here from Section 2.2.6 is that the job-finding probability, $\lambda_{w}$, is now a function of the wealth level, so consumers with different levels of $a_{0}$ have different expected present values of the extra UI receipt. As a result, the actuarially fair insurance premium depends on $a_{0}$ in addition to employment status at time 0 .

I denote as $Z_{t}^{i}\left(a_{t}\right)$ the expected present value of the extra UI receipt (that is, $\tilde{b}-b$ ) from time $t$ by a consumer with the employment state $i$ and the asset level $a_{t}$. Then, it can be 


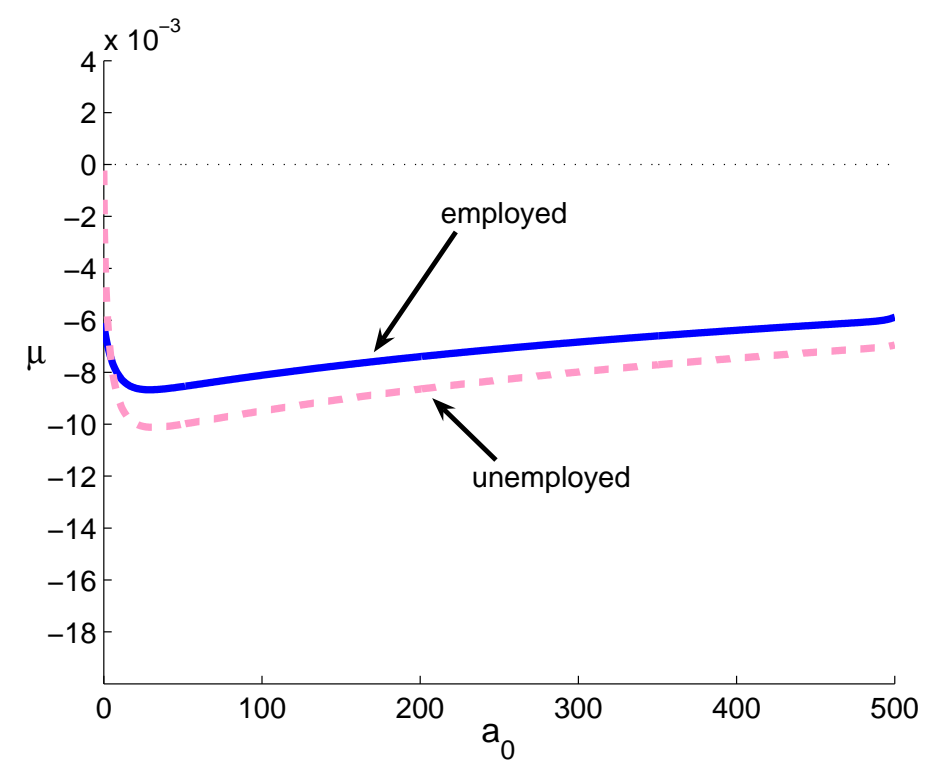

Figure 16: Welfare effects of the policy change: pure insurance effect

recursively calculated as

$$
Z_{t}^{u}\left(a_{t}\right)=\tilde{b}-b+\frac{1}{1+r_{t+1}-\delta}\left[\lambda_{w}\left(\varphi_{t}^{u}\left(a_{t}\right)\right) Z_{t+1}^{e}\left(\psi_{t}^{u}\left(a_{t}\right)\right)+\left(1-\lambda_{w}\left(\varphi_{t}^{u}\left(a_{t}\right)\right)\right) Z_{t+1}^{u}\left(\psi_{t}^{u}\left(a_{t}\right)\right)\right]
$$

and

$$
Z_{t}^{e}\left(a_{t}\right)=\frac{1}{1+r_{t+1}-\delta}\left[(1-\sigma) Z_{t+1}^{e}\left(\psi_{t}^{e}\left(a_{t}\right)\right)+\sigma Z_{t+1}^{u}\left(\psi_{t}^{e}\left(a_{t}\right)\right)\right],
$$

where $\psi_{t}^{i}\left(a_{t}\right)$ is the decision rule for $t+1$-period asset holdings by a consumer whose employment state is $i$ and asset level is $a_{t}$, and $\varphi_{t}^{u}\left(a_{t}\right)$ is the job search effort choice by an unemployed consumer with asset level $a_{t}$. After $Z_{t}^{i}\left(a_{t}\right)$ is calculated, the time- $t$ insurance premium for a consumer with the wealth level $a_{0}$ and the employment status $i, \tau_{t}^{i}\left(a_{0}\right)$, can be given by

$$
\tau_{t}^{i}\left(a_{0}\right)=\frac{r_{t}-\delta}{1+r_{t}-\delta} Z_{0}^{i}\left(a_{0}\right)
$$

for $i=e, u$. As in Section 2.2.6, $\tau_{t}^{i}\left(a_{0}\right)$ is subtracted from the consumer's income in each period.

The welfare effects are plotted in Figure 16. All consumers incur a welfare loss, of a similar magnitude as in the full experiment (Figure 11). Figures 11 and 16 look similar in terms of the difference in asset levels. This is because the price effect in Figure 12 and the implicit transfer built into Figure 15 cancel each other out.

A significant difference between Figure 16 and Figure 11 is that now the unemployed consumers lose more. Here, the welfare effect picks up the negative effect of moral hazard in addition to the positive effect of further access to insurance. Because individuals do not take 
into account the fact that their effort choice affects the insurance premium, they put less effort into searching for a job than the optimal level, and end up unemployed for too long and pay too much in insurance premiums. This deadweight loss affects all consumers negatively. In particular, the unemployed consumers are affected more because they are more likely to be in the unemployment pool for longer in near future, relative to the employed consumers.

\section{Model 3: Search and matching model}

In this section, I consider another model where the unemployment rate responds endogenously to the UI benefit. Here, I focus on the labor demand side and employ a Pissarides (1985)-type search and matching model. This type of model has also been used for the analysis of UI in other papers. Examples include Pollak (2007), Reichling (2007), and Krusell et al. (2009a). The model is mainly based on Krusell et al. (2009a). The main difference here from the analysis of Krusell et al. (2009a) is that I explicitly consider the transition dynamics, whereas they focus on the steady-state comparison.

\subsection{Setup}

There are consumers with population of measure one, and there is one representative firm which uses capital and labor as input. The firm is owned by the consumers through tradable equity. The firm cannot hire workers immediately: they have to post a vacancy, and with some probability the vacancy is filled. The firm can be viewed as a collection of the filled jobs, each of which generates profit. Note that the consumers can own the equity of the entire firm (that is, the claim to the total profit), and are not allowed to own the claim for the profit of an individual job. The frictions in the labor market are summarized by the aggregate matching function:

$$
M\left(u_{t}, v_{t}\right)=\chi u_{t}^{\eta} v_{t}^{1-\eta}
$$

where $\eta \in(0,1)$ and $\chi>0$ are parameters. $M\left(u_{t}, v_{t}\right)$ represents the amount of match at time $t$ when there are $u_{t}$ unemployed consumers and $v_{t}$ vacancies posted by the firm. The matching is entirely random. Therefore, the probability that a vacancy finds a worker is

$$
\lambda_{f}\left(\theta_{t}\right)=\chi\left(\frac{v_{t}}{u_{t}}\right)^{-\eta}=\chi \theta_{t}^{-\eta}
$$

and the probability that an unemployed consumer finds a job is

$$
\lambda_{w}\left(\theta_{t}\right)=\chi\left(\frac{v_{t}}{u_{t}}\right)^{1-\eta}=\chi \theta_{t}^{1-\eta}
$$

where $\theta_{t} \equiv v_{t} / u_{t}$ represents the labor market tightness at time $t$.

Consumers own two types of assets: capital stock, $k_{t}$, and equity, $x_{t}$. The capital stock is a factor of production, as in the previous models. The equity is the ownership of the 
representative firm, which consists of many jobs (filled vacancies) that generate profit. This profit is paid out to the equity holders as dividends every period. I normalize the total amount of equity to 1 and denote the post-dividend unit price of equity at time $t$ as $p_{t}$. Let the amount of the dividend at time $t$ be $d_{t}$. Since there is no aggregate uncertainty in this economy and the returns from capital and equity only depend on aggregate conditions, their returns must be the same. Therefore,

$$
\frac{d_{t+1}+p_{t+1}}{p_{t}}=1+r_{t+1}-\delta
$$

holds.

The consumer's budget constraint is

$$
c_{t}+k_{t+1}+p_{t} x_{t+1}=\left(1+r_{t}-\delta\right) k_{t}+\left(p_{t}+d_{t}\right) x_{t}+\mathcal{E}_{t},
$$

where $\mathcal{E}_{t}$ is after-tax labor earnings (including UI benefit) at time $t$. Once I define $a_{t} \equiv$ $k_{t}+p_{t-1} x_{t}$, using (4), this can be rewritten as

$$
c_{t}+a_{t+1}=\left(1+r_{t}-\delta\right) a_{t}+\mathcal{E}_{t} .
$$

Thus this budget constraint is identical to the previous sections. Since the two assets have identical returns, the portfolio choice of each consumer is indeterminate. However, the portfolio composition affects how each consumer is affected by the unanticipated policy change in the following experiments. In the following, I assume that all consumers hold the same proportions of capital and equity (that is, $k_{t} / x_{t}$ is same for all the consumers).

Consumers maximize utility (1). The wage is determined by Nash bargaining between the firm and the worker every period. The Nash bargaining process is detailed later. It turns out that the wage is a function of the worker's current wealth, and I denote the wage $w_{t}$ as a function $w_{t}=\omega_{t}\left(a_{t}\right)$. Then, an employed consumer's Bellman equation and an unemployed consumer's Bellman equation can be written as

$$
W_{t}\left(a_{t}\right)=\max _{c_{t}, a_{t+1}} \log \left(c_{t}\right)+\beta\left[(1-\sigma) W_{t+1}\left(a_{t+1}\right)+\sigma U_{t+1}\left(a_{t+1}\right)\right]
$$

subject to

$$
c_{t}+a_{t+1}=\left(1+r_{t}-\delta\right) a_{t}+\omega_{t}\left(a_{t}\right) \bar{h}-T_{t}
$$

and

$$
a_{t+1} \geq \underline{a},
$$

and

$$
U_{t}\left(a_{t}\right)=\max _{c_{t}, a_{t+1}} \log \left(c_{t}\right)+\beta\left[\lambda_{w}\left(\theta_{t}\right) W_{t+1}\left(a_{t+1}\right)+\left(1-\lambda_{w}\left(\theta_{t}\right)\right) U_{t+1}\left(a_{t+1}\right)\right]
$$

subject to

$$
c_{t}+a_{t+1}=\left(1+r_{t}-\delta\right) a_{t}+b-T_{t}
$$

and

$$
a_{t+1} \geq \underline{a} .
$$


Let the decision rules for the next period asset be $a_{t+1}=\psi_{t}^{i}\left(a_{t}\right)$, where $i=e$ for an employed consumer and $i=u$ for an unemployed consumer.

The firm's objective is to maximize the discounted present value of its profits for the shareholders. From (4), the shareholders discount the future profit by the rate $\left(1+r_{t+1}-\delta\right)$. To produce, the firm has to create jobs and rent capital. The production function for each job is $k^{\alpha} \bar{h}^{1-\alpha}$, where $k$ is the rented capital and $\alpha \in(0,1)$. As in the previous sections, $\bar{h}$ is the fixed working hours for each employed consumer. To create a job, the firm has to first post a vacancy. The flow cost of posting a vacancy is $\xi$, and each vacancy faces a probability $\lambda_{f}\left(\theta_{t}\right)$ of finding a worker. Because the matching process is random, each vacancy can be filled by any worker, but the resulting profit can differ depending on the worker's wealth level. Because the wage depends on the worker's wealth level, matching with one worker can be more beneficial than matching with another worker. In the following quantitative exercise, it turns out that all the matchings are beneficial for the firm. I denote the value from matching with a worker with asset level $a_{t}$ at time $t$ as $J_{t}\left(a_{t}\right)$. The probability density of the unemployed consumers whose asset level is $a_{t}$ at time $t$ is $f_{t}^{u}\left(a_{t}\right) / u_{t}$, where $f_{t}^{u}\left(a_{t}\right)$ is the measure of unemployed consumers with asset level $a_{t}$ at time $t$. Thus, the expected value of the match in the next period (conditional on matching) is $\int J_{t+1}\left(\psi_{t}^{u}(a)\right)\left(f_{t}^{u}(a) / u_{t}\right) d a$. The value of posting a vacancy at time $t$, $V_{t}$, is therefore

$$
V_{t}=-\xi+\frac{1}{1+r_{t+1}-\delta}\left[\left(1-\lambda_{f}\left(\theta_{t}\right)\right) V_{t+1}+\lambda_{f}\left(\theta_{t}\right) \int J_{t+1}\left(\psi_{t}^{u}(a)\right) \frac{f_{t}^{u}(a)}{u_{t}} d a\right] .
$$

I assume free entry to vacancy posting, so that in equilibrium $V_{t}=0$ in (5) for all $t$ with a positive amount of vacancy posting. The free entry condition determines the equilibrium value of $\theta_{t}$ (and therefore $v_{t}$ ) every period.

The value of a filled job is

$$
J_{t}\left(a_{t}\right)=\max _{k} \quad k^{\alpha} \bar{h}^{1-\alpha}-r_{t} k-\omega_{t}\left(a_{t}\right)+\frac{1}{1+r_{t+1}-\delta}\left[(1-\sigma) J_{t+1}\left(\psi_{t}^{e}\left(a_{t}\right)\right)+\sigma V_{t+1}\right] .
$$

The firm's first-order condition for $k$ is

$$
r_{t}=\alpha k^{\alpha-1} \bar{h}^{1-\alpha}
$$

Let $K_{t}$ be the aggregate capital stock. Because there are $\left(1-u_{t}\right)$ filled jobs that have an identical productivity, each job employs $\tilde{k}_{t} \equiv K_{t} /\left(1-u_{t}\right)$ amount of capital stock in equilibrium. Therefore, the equilibrium interest rate is:

$$
r_{t}=\alpha \tilde{k}_{t}^{\alpha-1} \bar{h}^{1-\alpha}
$$

Denoting $L_{t}=\left(1-u_{t}\right) \bar{h}$ as the aggregate labor input, this can also be rewritten as

$$
r_{t}=\alpha\left(\frac{K_{t}}{L_{t}}\right)^{\alpha-1}
$$


As in the previous models, this makes it clear that $r_{t}$ is a decreasing function of $K_{t} / L_{t}$.

To analyze the wage bargaining, first consider the auxiliary problem for an employed consumer with a given wage level $w$ :

$$
\tilde{W}_{t}\left(w, a_{t}\right)=\max _{c_{t}, a_{t+1}} \log \left(c_{t}\right)+\beta\left[(1-\sigma) W_{t+1}\left(a_{t+1}\right)+\sigma U_{t+1}\left(a_{t+1}\right)\right]
$$

subject to

$$
c_{t}+a_{t+1}=\left(1+r_{t}-\delta\right) a_{t}+w \bar{h}-T_{t}
$$

and

$$
a_{t+1} \geq \underline{a} .
$$

Let the solution to this problem for $a_{t+1}$ be $a_{t+1}=\tilde{\psi}_{t}^{e}\left(w, a_{t}\right)$. The auxiliary problem for the firm is

$$
\tilde{J}_{t}\left(w, a_{t}\right)=\max _{k} \quad k^{\alpha} \bar{h}^{1-\alpha}-r_{t} k-w+\frac{1}{1+r_{t+1}-\delta}\left[(1-\sigma) J_{t+1}\left(\tilde{\psi}_{t}^{e}\left(w, a_{t}\right)\right)+\sigma V_{t+1}\right] .
$$

Given these values, the wage is determined by Nash bargaining:

$$
\omega_{t}\left(a_{t}\right)=\arg \max _{w}\left(\tilde{W}_{t}\left(w, a_{t}\right)-U_{t}\left(a_{t}\right)\right)^{\gamma}\left(\tilde{J}_{t}\left(w, a_{t}\right)-V_{t}\right)^{1-\gamma} .
$$

The profit for each job can be calculated as

$$
\pi_{t}\left(a_{t}\right)=\tilde{k}_{t}^{\alpha} \bar{h}^{1-\alpha}-r_{t} \tilde{k}_{t}-\omega_{t}\left(a_{t}\right) .
$$

Aggregating each firm's profit (minus the vacancy cost) yields the dividend:

$$
d_{t}=\int \pi_{t}(a) f_{t}^{e}(a) d a-\xi v_{t} .
$$

With $d_{t}$, the equity price $p_{t}$ can be calculated from (4) and an appropriate transversality condition, using the equilibrium interest rate (6).

The asset market equilibrium condition determines the value of $K_{t}$ at each period. From the definition of $a_{t}$ for each consumer (and indexing each consumer by the superscript $i$ ),

$$
\int k_{t+1}^{i} d i+\int p_{t} x_{t+1}^{i} d i=\int a_{t+1}^{i} d i
$$

has to hold. Because $\int k_{t+1}^{i} d i=K_{t+1}$ and $\int x_{t+1}^{i} d i=1$ hold in equilibrium,

$$
K_{t+1}=\int a_{t+1}^{i} d i-p_{t} .
$$

At the aggregate level, the unemployment rate moves following the transition equation

$$
u_{t+1}=\sigma\left(1-u_{t}\right)+\left(1-\lambda_{w}\left(\theta_{t}\right)\right) u_{t} .
$$

The government balances the budget every period:

$$
T_{t}=u_{t} b
$$




\subsection{Results}

The assigned parameter values are the same as in Section 2 for the common parameters. There are four additional parameters here: $\chi, \eta, \gamma$, and $\xi$. I follow Shimer (2005) and set $\eta=\gamma=0.72$. I assume that (again, following Shimer (2005)) the baseline value of $\theta$ is 1 , that is, $\theta=1$ in the steady state before the policy change. This means that the job-finding rate $\lambda_{w}\left(\theta_{t}\right)$ is equal to $\chi$ in the steady state before the policy change. I set $\chi=0.26$, to be consistent with the job-finding probability in Section 2. The value of $\xi$ is set so that the free-entry condition $V_{t}=0$ is satisfied with $V_{t}$ in (5) before the policy change (with $\theta=1$ ). This procedure provides $\xi=0.354$. The computational method is similar to Krusell et al. (2009a) and thus the details are omitted here. The benchmark steady state features an asset distribution that looks similar to the previous sections.

\subsubsection{Full experiment}

As in Section 2.2.1, I examine the policy experiment which unexpectedly changes the UI benefit from $b=0.27$ to $\tilde{b}=0.90$ at time 0 . I assume that the economy is in the steady state with benefit level $b$ before time 0 . At time 0 , some variables jump, and some variables experience gradual transitions towards the new steady state.

There are five channels through which an increase in $b$ influences individual welfare. First, the increase in $b$ directly increases income while unemployed. Second, the increase in $b$ leads to a tax increase. Third, the increase in $b$ insures the consumers against unemployment risk. Fourth, the reduction in risk reduces precautionary savings, and leads to the eventual decline in $K_{t} / L_{t}$. These four effects are present in the previous two models, and analyzed in detail below.

The fifth channel is unique to the search-matching model. This comes through the wage bargaining process. An increase in $b$ increases the worker's value outside of employment, and therefore increases the worker's bargaining power. This leads to a higher wage and a lower profit for the firm. A lower profit, in turn, decreases the incentive for the firm to post vacancies. As a result, $v_{t}$ falls, and thus $\theta_{t}=v_{t} / u_{t}$ falls, and as a consequence the job-finding probability $\lambda_{w}\left(\theta_{t}\right)$ falls. This leads to a gradual increase in the unemployment rate. Therefore, in the end, an increase in $b$ leads to an increase in the unemployment rate, as in Section 3. However, the mechanism here is entirely different-in Section 3, the job-finding rate decreases because of the reduced search effort by the consumer (labor supply effect), whereas here the job-finding rate falls because of the reduced vacancy postings by the firm (labor demand effect). Another consequence of the decreased profit is that the equity price jumps down at the beginning of time 0 (at the moment the policy change occurs). In particular, from (4),

$$
p_{-1}=\frac{d_{0}+p_{0}}{1+r_{0}-\delta} \text {. }
$$

Because $d_{t}$ and $r_{t}$ for $t=0,1,2, \ldots$ change due to the policy change, $p_{-1}$ (the equity price before the time-0 asset market opens) has to be re-evaluated to be consistent with the new 


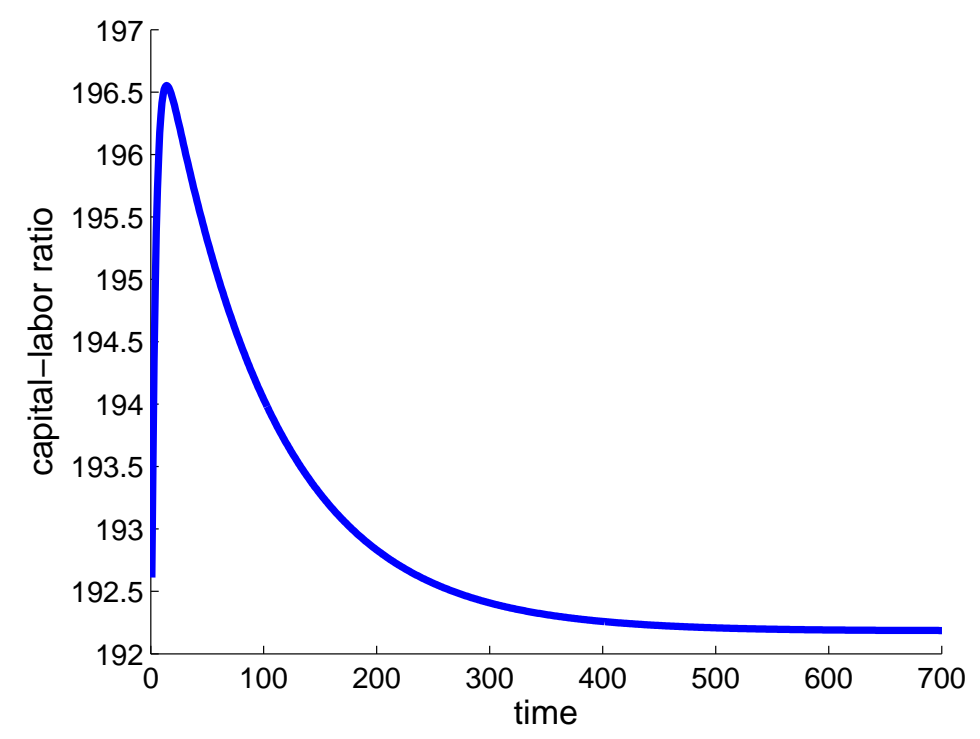

Figure 17: Transition path of aggregate capital-labor ratio $\left(K_{t} / L_{t}\right)$ after the policy change

environment. Because $a_{0}=k_{0}+p_{-1} x_{0}, a_{0}$ has to be re-evaluated because of the fall in $p_{-1}$. I assume that $k_{0} / x_{0}$ is common for everyone, therefore everyone incurs a capital loss (a fall in $\left.a_{0}\right)$ due to the fall in $p_{-1}$.

Figure 17 plots the time path of the capital-labor ratio. As in Section 3.2.1 (Figure 10), $K_{t} / L_{t}$ increases first, and then declines to a level which is lower than the original level. Again, it reflects the fact that the adjustment of $L_{t}$ (increase of $u_{t}$ ) is much faster than the adjustment of $K_{t}$. The new steady-state value of $u_{t}$ is $9.3 \%$. In calculating the welfare effect, the effect of an initial increase in $K_{t} / L_{t}$ dominates the effect of the eventual decline.

Figure 18 plots the welfare effect. Most of the consumers experience a welfare loss. ${ }^{19}$ In

\footnotetext{
${ }^{19}$ When the utility function is linear, the Hosios condition (see Hosios (1990) and Pissarides (2000, Ch. 8)) guarantees the Pareto efficiency of the outcome. It is also known that a similar condition holds in the concave utility setting with complete asset markets (see Merz (1995) and Andolfatto (1996)). The Hosios condition is expressed as $\eta=\gamma$ in our notation. Intuitively, this balances (i) the negative externality of vacancy postings in the matching process (too many vacancy postings if the posting is fully rewarded) and (ii) the (insufficient) reward from the vacancy posting (the worker gets a share of the benefit). The first effect is large when $\eta$ is large (more curvature in the matching function on the vacancy side) and the second effect is large when $\gamma$ is large (lower share for the firm). If $\eta>\gamma$, there are too many vacancy postings and if $\eta<\gamma$ there are too few vacancy postings. Because I set $\eta=\gamma$ in the calibration, the optimal UI benefit is zero when the asset market is complete. Therefore, it is natural that I obtain a negative effect from increasing the UI benefit overall. If I set $\eta>\gamma$ instead, the welfare gain from increasing the UI benefit should be larger. Appendix $\mathrm{C}$ formally shows that the optimal unemployment insurance (when "optimal" is defined as maximizing the discounted present value of output subject to the search frictions) is strictly positive if and only if $\eta>\gamma$ when the utility function is linear. Appendix D conducts the same experiments as in this section with the parametrization of $\gamma-0.5$ (and therefore
} 


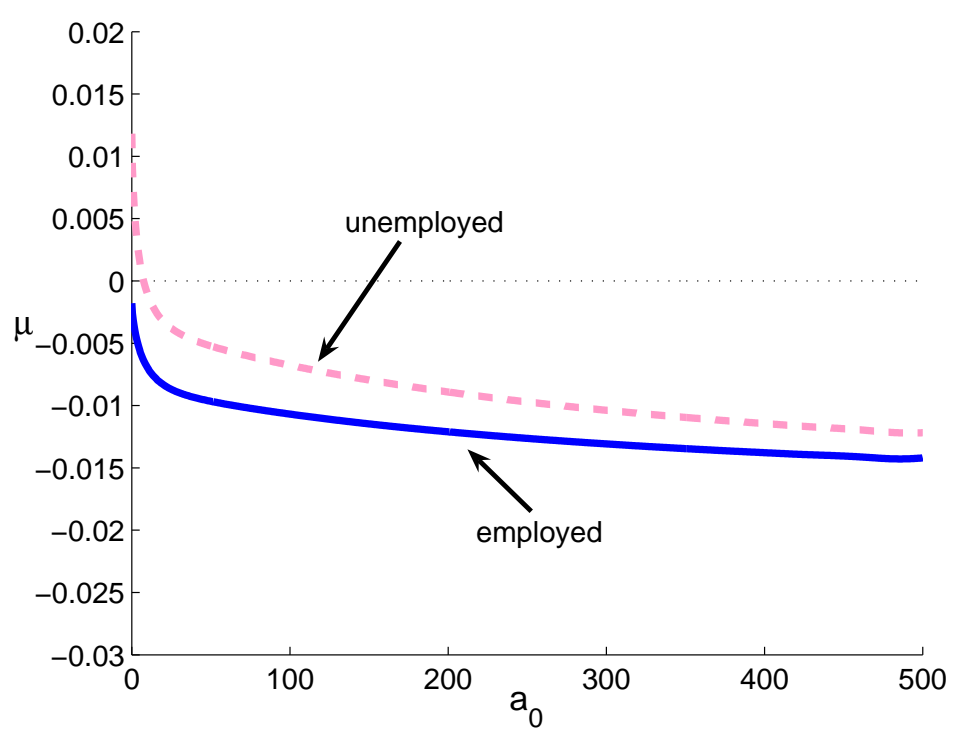

Figure 18: Welfare effects of the policy change

the following, I decompose this welfare effect into different factors.

\subsubsection{Decomposition 1: Price effect}

In this section, I consider the effect of a change in prices. The experiment is the same as in Sections 2.2.2 and 3.2.2: I feed in the equilibrium prices from 4.2.1 and keep everything else the same as in the benchmark steady-state. Here, the prices include three objects: interest rate, wage, and equity price. There are two significant differences from the analysis of the previous models. First, although the time path of $r_{t}$ is common to everyone, wages can be different across workers depending on their asset levels. Instead of one wage level, I feed in the wage functions $\omega_{t}\left(a_{t}\right)$ at each $t$ from the results of Section 4.2.1. Second, the equity price jumps down at the point of the policy change at time 0 . The consumers who hold equity incur a one-time capital loss. (After time 0, the equity price satisfies (4) again, so that it can be treated as the same asset as the capital stock.) I feed in the same equity prices after the policy change as in Section 4.2.1, assuming that the portfolio choice is identical across the consumers (that is, $k_{t} / x_{t}$ is common). Thus, everyone incurs the same degree of capital loss relative to her total asset holding.

Figure 17 and equation (6) imply that $r_{t}$ first goes down, and then goes up. The immediate impact (that is, falling) dominates, and this causes a welfare loss to high-wealth consumers. Figure 19 plots the path of the average wage after the change in policy, and it indicates that $\overline{\eta>\gamma}$ ) and shows that indeed the desirability a high UI benefit increases in that case. 


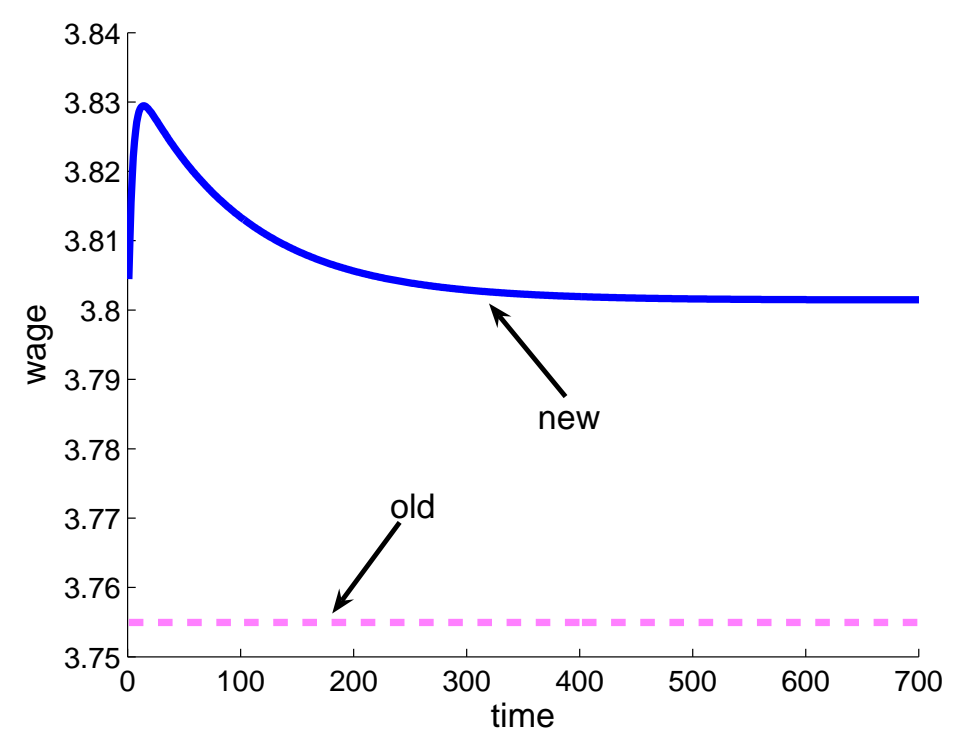

Figure 19: Transition path of the average wage after the policy change

the wage increases relative to the old level (before the policy change), reflecting the increase in the consumer's bargaining power. This benefits all consumers, in particular the ones whose income mainly consists of labor income. Of course, this benefit is (at least partially) offset by the capital loss due to the drop in equity price at time 0.

Figure 20 plots the welfare effects of these price changes. The picture is qualitatively similar to the moral hazard case (Figure 12). This is because in both cases, the main effects that creates conflicts across different consumers are the decrease in $r_{t}$ and increase in $w_{t}$. (The drop in equity price affects everyone in a similar manner.) Although the mechanisms to change $w_{t}$ are different, the mechanism for the change in $r_{t}$ is identical across consumers. The lesson here (as in Section 3) is that $L_{t}$ tends to adjust much more quickly than $K_{t}$, and therefore the immediate impact on $r_{t}$ is opposite to the case where only $K_{t}$ changes.

\subsubsection{Decomposition 2: Matching effect}

One feature of the current model that is different from the previous model is that the change in the job-finding probability comes as an "exogenous" change from the viewpoint of a consumer (in the sense that it is outside her control). Here I evaluate how this change affects the consumer's welfare. To this end, I analyze the consumers' welfare when the time series of $\lambda_{w}\left(\theta_{t}\right)$ is the same as in Section 4.2.1, keeping everything else the same as the benchmark.

Figure 21 plots the result. Because the job-finding probability falls, everyone incurs a welfare loss. In particular, it hurts the unemployed consumers more because the impact of the job-finding probability is more immediate for them. 


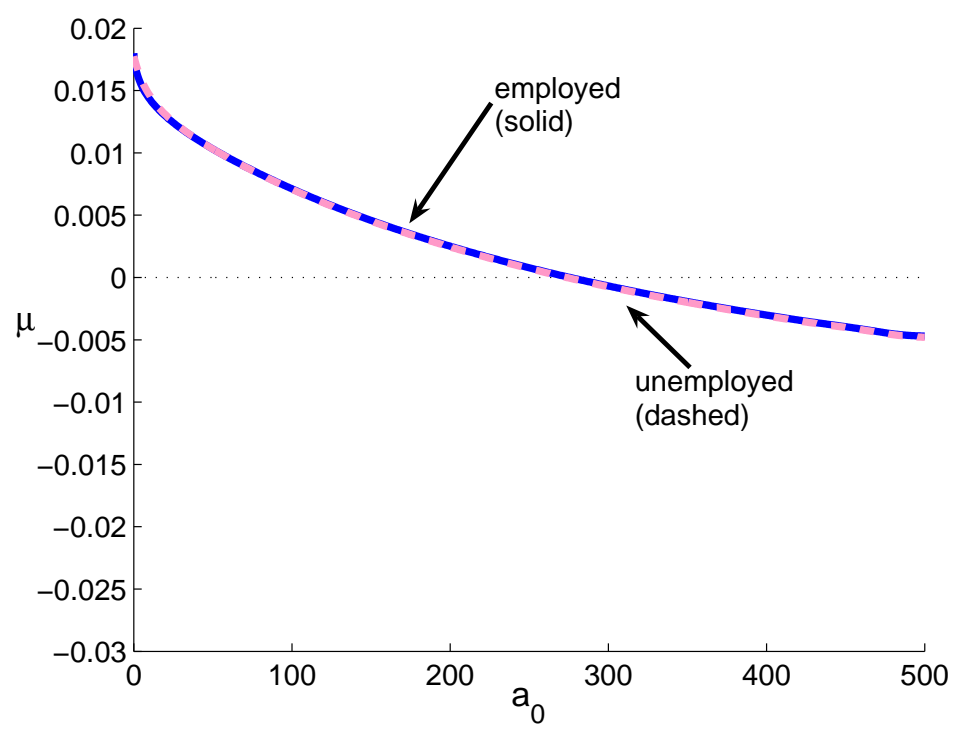

Figure 20: Welfare effects of the policy change: price effect

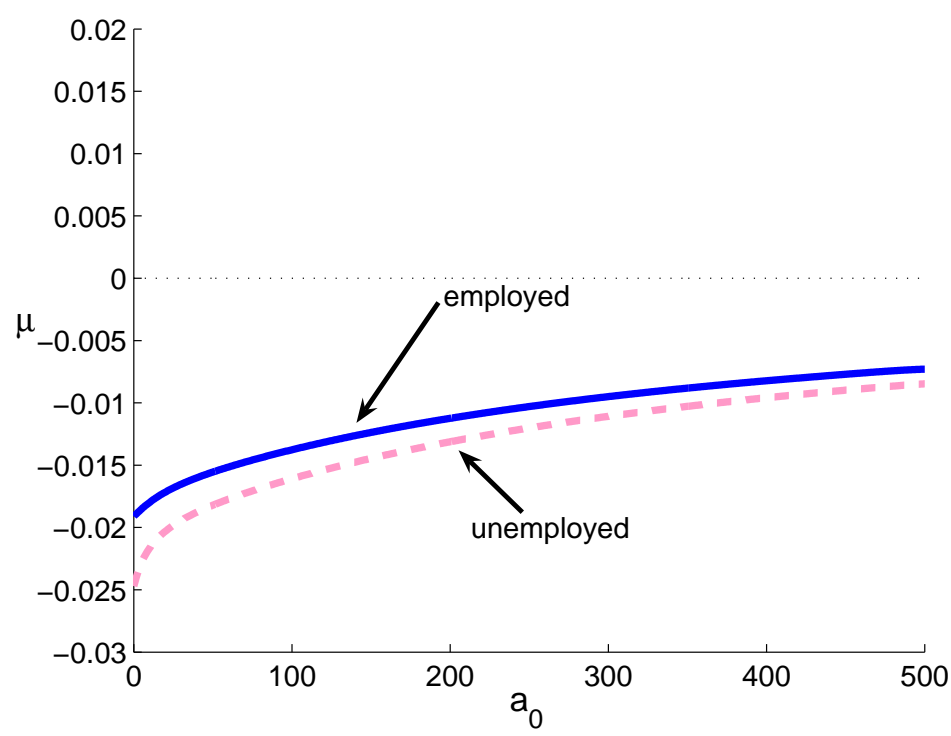

Figure 21: Welfare effects of the policy change: matching effect 


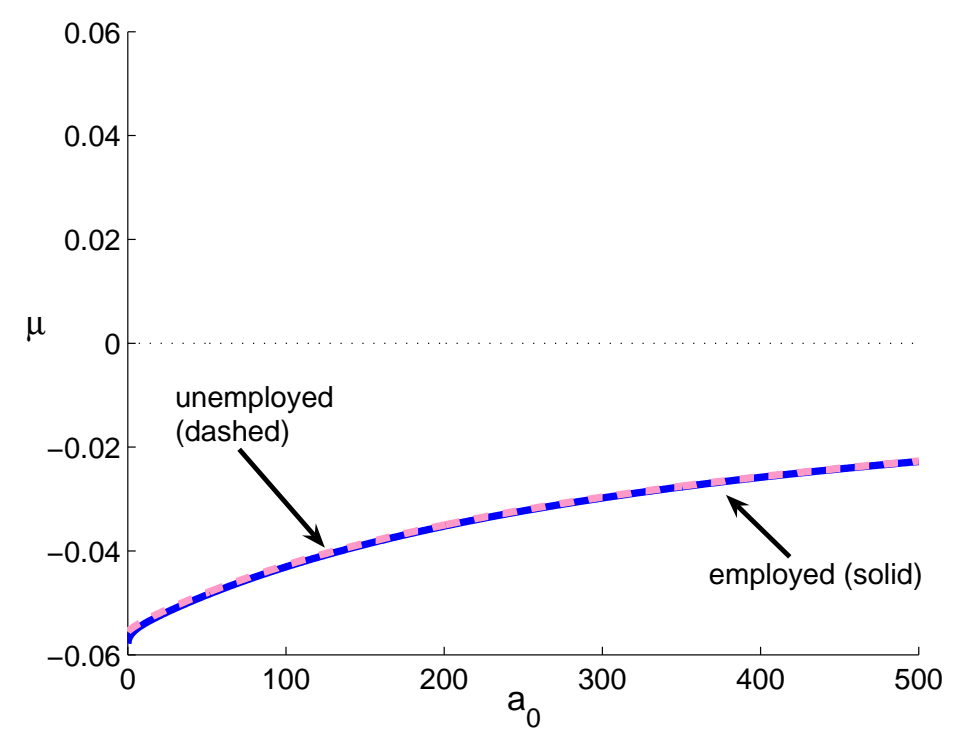

Figure 22: Welfare effects of the policy change: tax effect

The price effect and the matching effect are similar in magnitude. Combining them cancels out to almost zero for very poor consumers, but both are negative for very rich consumers.

\subsubsection{Decomposition 3: Tax effect}

Figure 22 plots the welfare effect when the tax is changed to $\tilde{T}_{t}$, keeping everything else the same. Everyone experiences a welfare loss.

\subsubsection{Decomposition 4: Benefit only}

Figure 23 plots the welfare effect when the benefit is changed to $\tilde{b}$, keeping everything else the same. Everyone receives a positive welfare gain. The gains are higher for unemployed consumers, because they have an immediate chance of enjoying the higher benefit.

\subsubsection{Decomposition 5: Tax and benefit combined}

Again, large parts of the tax effect and the benefit effect cancel out. To see the net effect, in this section I change both the benefit and the tax to the new level $\left(\tilde{b}\right.$ and $\left.\tilde{T}_{t}\right)$, while keeping everything else the same. Figure 24 plots the welfare effects. The reason why the net effect is negative for almost all consumers is that $\tilde{T}_{t}$ reflects the increase in the unemployment rate in the future. Because I use $\lambda_{w}\left(\theta_{t}\right)$ from the benchmark (that is, a constant value at the old level), this tax is not a "fair" tax from the viewpoint of consumers - consumers pay a tax based 


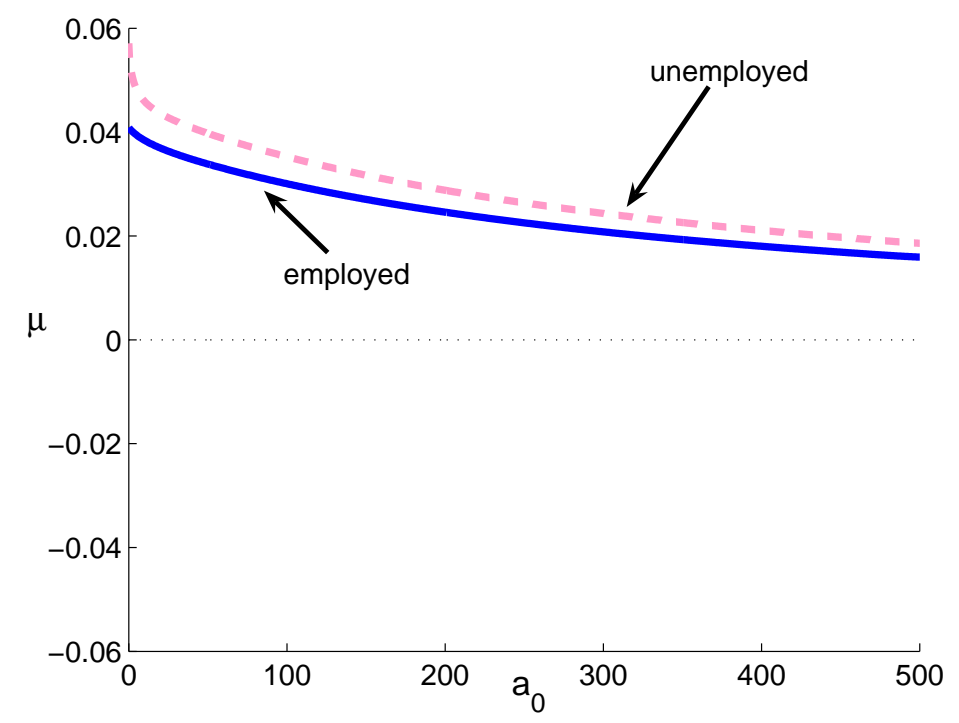

Figure 23: Welfare effects of the policy change: benefit effect

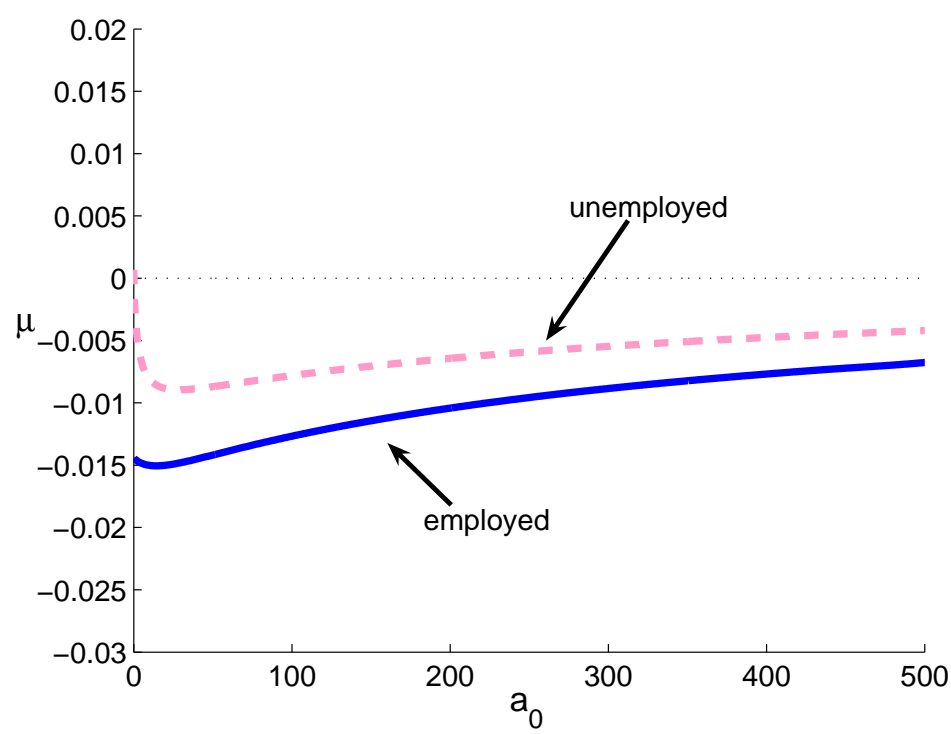

Figure 24: Welfare effects of the policy change: tax effect and benefit effect together 
on the unemployment rate that is higher than the one they should face based on their actual duration of unemployment.

The reason why the employed consumers lose more in Figure 24 is that the employed consumers have less of a chance than the unemployed consumers of enjoying a higher benefit. The implicit transfer effect from unemployed consumers to employed consumers is still present here, as in the previous sections.

\subsubsection{Decomposition 6: Pure insurance effect}

As in Sections 2.2.6 and 3.2.6, I measure the "pure insurance effect" by making consumers pay the pure insurance premium for the extra UI benefit. I denote as $Z_{t}^{i}$ the expected present value of the extra UI received (that is, $\tilde{b}-b$ ) after time $t$ by a consumer with employment state $i$. Then,

$$
Z_{t}^{u}=\tilde{b}-b+\frac{1}{1+r_{t+1}-\delta}\left[\lambda_{w}\left(\theta_{t}\right) Z_{t+1}^{e}+\left(1-\lambda_{w}\left(\theta_{t}\right)\right) Z_{t+1}^{u}\right]
$$

and

$$
Z_{t}^{e}\left(a_{t}\right)=\frac{1}{1+r_{t+1}-\delta}\left[(1-\sigma) Z_{t+1}^{e}+\sigma Z_{t+1}^{u}\right] .
$$

Then, the time- $t$ insurance premium for a consumer with employment status $i, \tau_{t}^{i}$, is

$$
\tau_{t}^{i}=\frac{r_{t}-\delta}{1+r_{t}-\delta} Z_{0}^{i}
$$

for $i=e, u . \tau_{t}^{i}$ is subtracted from the consumer's income in each period.

Figure 25 plots the welfare effects. The figure is very similar to Figure 8: everyone gains from access to the extra insurance, but only very poor consumers experience a significant amount of welfare gain.

\section{Conclusion}

This paper analyzed three general equilibrium models to understand the welfare effects of the UI policy. The three models provided very different pictures of the welfare effect of the increase in the UI benefit. In terms of the individual level pure-insurance effect, the exogenous unemployment model and the search-matching model yielded a similar result: access to the extra UI (with an actuarially fair premium) benefits all the consumers, but only the very poor consumers experience a significant welfare gain. In the moral hazard model, the negative effect of moral hazard overwhelms an individual's benefits from further insurance.

The price effect is one source of conflict between wealthy and poor consumers. It turned out that the results of the exogenous unemployment model are misleading. The price effect there solely depends on the change in capital stock, while if the unemployment rate is endogenous the labor market adjustment is much faster than the change in capital stock and it influences welfare much more. 


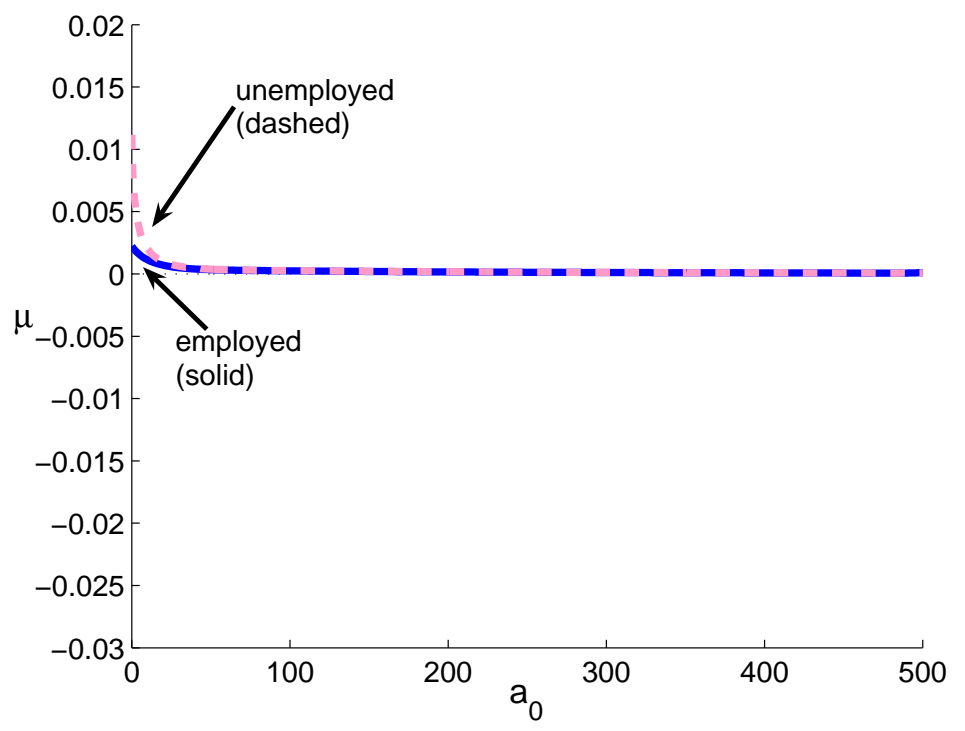

Figure 25: Welfare effects of the policy change: pure insurance effect

The change in the UI benefit and in the tax involves implicit transfers across agents. The main transfer that is present in all of the models is the one between the consumers who are currently unemployed and the consumers who are currently employed. Since the UI benefit only affects the unemployed consumers while the tax is charged to everyone, the consumers who are currently unemployed receive a net gain in the expected present value of income. In the moral hazard model, there is also a transfer from poor to wealthy consumers: because wealthy consumers do not search as hard as poor consumers, they tend to spend more time in the unemployment pool.

In the matching model, the change in the job-finding probability is "exogenous" from the viewpoint of a consumer (in the sense that she cannot influence it by her individual behavior). The decline in the job-finding probability hurts unemployed consumers more than employed consumers.

The comparison of the three models shows that the resulting welfare effects are very different across different models, although they share the same structure in the consumer's optimization and the firm's production. This means that the details of labor market modeling matter significantly in determining the quantitative outcome.

I believe that the decomposition employed in this paper is useful also in analyzing other policy issues, in particular when the welfare effects of the policy are affected by many different factors. The analysis in this paper also complements the recent research on measuring and understanding the extent of insurance available to consumers in the current U.S. economy, such as Blundell et al. (2008), Heathcote et al. (2008), and Kaplan and Violante (2009). Incorporating 
other social insurance policies into the analysis (and considering other kinds of risks), as in Low et al. (2008) is an important line of future research. Another important extension is to consider a more sophisticated unemployment insurance policy, in which the tax and the benefit levels depend on observable individual and aggregate states as well as observable histories. 


\section{References}

[1] Abdulkadiroğlu, Atila; Burhanettin Kuruşçu; and Ayşegül Şahin (2002). "Unemployment Insurance and the Role of Self-Insurance," Review of Economic Dynamics 5, 681-703.

[2] Andolfatto, David (1996). "Business Cycles and Labor Market Search," American Economic Review 86, 112-132.

[3] Andolfatto, David and Paul Gomme (1996). "Unemployment Insurance and Labor-Market Activity in Canada," Carnegie-Rochester Conference Series on Public Policy 44, 47-82.

[4] Bewley, Truman F. (undated). "Interest Bearing Money and the Equilibrium Stock of Capital," mimeo.

[5] Blundell, Richard; Luigi Pistaferri; and Ian Preston (2008). "Consumption Inequality and Partial Insurance," American Economic Review 98, 1887-1921.

[6] Budría Rodríguez, Santiago; Javier Díaz-Giménez; Vincenzo Quadrini; and José-Víctor Ríos-Rull (2002). "Updated Facts on the U.S. Distributions of Earnings, Income, and Wealth," Federal Reserve Bank of Minneapolis Quarterly Review 26, 2-35.

[7] Doepke, Matthias and Martin Schneider (2006). "Inflation and the Redistribution of Nominal Wealth," Journal of Political Economy 114, 1069-1097.

[8] Gruber, Jonathan (1997). "The Consumption Smoothing Benefits of Unemployment Insurance," American Economic Review 87, 192-205.

[9] Heathcote, Jonathan; Kjetil Storesletten; and Giovanni L. Violante (2008). "Insurance and Opportunities: A Welfare Analysis of Labor Market Risk," Journal of Monetary Economics $55,501-525$.

[10] Hansen, Gary D. and Ayşe İmrohoroğlu (1992). "The Role of Unemployment Insurance in an Economy with Liquidity Constraints and Moral Hazard," Journal of Political Economy $100,118-142$.

[11] Hopenhayn, Hugo A. and Juan Pablo Nicolini (1997). "Optimal Unemployment Insurance," Journal of Political Economy 105, 412-438.

[12] Hosios, Arthur J. (1990). "On the Efficiency of Matching and Related Models of Search and Unemployment," Review of Economic Studies 57, 279-298.

[13] Huggett, Mark (1993). "The Risk-Free Rate in Heterogeneous-Agent Incomplete-Insurance Economies," Journal of Economic Dynamics and Control 17, 953-969.

[14] Kaplan, Greg and Giovanni L. Violante (2009). "How Much Insurance in Bewley Models?" mimeo. New York University. 
[15] Krusell, Per; Toshihiko Mukoyama; and Ayşegül Şahin (2009a). "Labor-Market Matching with Precautionary Savings and Aggregate Fluctuations," mimeo. Princeton University, University of Virginia, and Federal Reserve Bank of New York.

[16] Krusell, Per; Toshihiko Mukoyama; Ayşegül Şahin; and Anthony A. Smith, Jr. (2009b). "Revisiting the Welfare Effects of Eliminating Business Cycles," Review of Economic Dynamics 12, 393-404.

[17] Krusell, Per and Anthony A. Smith, Jr. (1998). "Income and Wealth Heterogeneity in the Macroeconomy," Journal of Political Economy 106, 867-896.

[18] Lentz, Rasmus (2009). "Optimal Unemployment Insurance in an Estimated Job Search Model with Savings," Review of Economic Dynamics 12, 37-57.

[19] Low, Hamish; Costas Meghir; and Luigi Pistaferri (2008). "Wage Risk and Employment Risk over the Life Cycle," IFS WP 08/06.

[20] Lucas, Robert E., Jr. (1987). Models of Business Cycles, Basil Blackwell, New York.

[21] Martin, John P. (1996). "Measures of Replacement Rates for the Purpose of International Comparisons: A Note," OECD Economic Studies 26, 99-115.

[22] Merz, Monika (1995). "Search in the Labor Market and the Real Business Cycle," Journal of Monetary Economics 36, 269-300.

[23] Meyer, Bruce D. (1990). "Unemployment Insurance and Unemployment Spells," Econometrica $58,757-782$.

[24] Mukoyama, Toshihiko (2010). "Welfare Effects of Unanticipated Policy Changes with Complete Asset Markets," mimeo. University of Virginia.

[25] Mukoyama, Toshihiko and Ayşegül Şahin (2006). "Costs of Business Cycles for Unskilled Workers," Journal of Monetary Economics 53, 2179-2193.

[26] Pissarides, Christopher A. (1985). "Short-Run Equilibrium Dynamics of Unemployment, Vancancies, and Real Wages," American Economic Review 75, 676-690.

[27] Pissarides, Christopher A. (2000). Equilibrium Unemployment Theory, Second Edition, MIT Press, Cambridge.

[28] Pallage, Stéphane and Christian Zimmermann (2001). "Voting on Unemployment Insurance," International Economic Review 42, 903-923.

[29] Pollak, Andreas (2007). "Optimal Unemployment Insurance with Heterogeneous Agents," European Economic Review 51, 2029-2053. 
[30] Reichling, Felix (2007). "Optimal Unemployment Insurance in Labor Market Equilibrium when Workers can Self-Insure," mimeo.

[31] Shavell, Steven and Laurence Weiss (1979). "The Optimal Payment of Unemployment Insurance Benefits over Time," Journal of Political Economy 87, 1347-1362.

[32] Shimer, Robert J. (2005). "The Cyclical Behavior of Equilibrium Unemployment and Vacancies," American Economic Review 95, 25-49.

[33] Shimer, Robert J. and Iván Werning (2008). "Liquidity and Insurance for the Unemployed," American Economic Review 98, 1922-1942.

[34] Wang, Cheng and Stephen Williamson (1996). "Unemployment Insurance with Moral Hazard in a Dynamic Economy," Carnegie-Rochester Conference Series on Public Policy 44, $1-41$.

[35] Wang, Cheng and Stephen Williamson (2002). "Moral Hazard, Optimal Unemployment Insurance, and Experience Rating," Journal of Monetary Economics, 49, 1337-1371.

[36] Young, Eric R. (2004). "Unemployment Insurance and Capital Accumulation," Journal of Monetary Economics 51, 1683-1710. 


\section{Appendix}

\section{A Exogenous unemployment model with stochastic $\beta$}

This section modifies the model in Section 2 so that the wealth distribution in the model matches the wealth distribution observed in the data. Similarly to Krusell and Smith (1998) and Krusell et al. (2009), I assume that the preferences are represented by the utility function

$$
\mathbf{U}=E\left[\sum_{t=0}^{\infty} B_{t} \log \left(c_{t}\right)\right]
$$

where $B_{t}$ is a stochastic variable which is idiosyncratic - i.i.d. across agents - and describes the cumulative discounting between period 0 and period $t$. In particular, $B_{t+1}=\tilde{\beta} B_{t}$, where $\tilde{\beta}$ is a three-state, first-order Markov process and $B_{0}$ is given. The difference from (1) is that the discount factor is stochastic over time and heterogenous across agents. $\tilde{\beta}$ can take three values: high $\left(\tilde{\beta}=\beta_{h}\right)$, middle $\left(\tilde{\beta}=\beta_{m}\right)$, and low $\left(\tilde{\beta}=\beta_{\ell}\right)$. In addition to the difference in preferences, the borrowing limit $\underline{a}$ is set at a strictly negative value.

Calibration of the Markov process for $\tilde{\beta}$ largely follows Krusell et al. (2009). In particular, I use three criteria: (i) in the stationary distribution, $80 \%$ of the population are on the middle value $\left(\tilde{\beta}=\beta_{m}\right)$ and $10 \%$ are on each extreme point $\left(\tilde{\beta}=\beta_{h}\right.$ and $\left.\tilde{\beta}=\beta_{\ell}\right)$ (ii) expected duration of the extreme discount values $\left(\tilde{\beta}=\beta_{h}\right.$ and $\left.\tilde{\beta}=\beta_{\ell}\right)$ is 50 years (approximating a lifetime) (iii) transitions can only occur to adjacent values (no direct transitions between $\beta_{h}$ and $\beta_{\ell}$ ). In addition, I require that (i) $\beta_{m}$ is the same value as in Section 2 , that is, $\beta_{m}=0.9967$ (ii) $\beta_{h}-\beta_{m}=\beta_{m}-\beta_{\ell}$ and (iii) the Gini coefficient in the model matches that of the data. This results in the values of $\tilde{\beta}_{\mathrm{s}}$ as $\beta_{h}=0.99755, \beta_{m}=0.9967$, and $\beta_{\ell}=0.99585$ and the Markov transition matrix (denoting the probability of moving from $\tilde{\beta}=\beta_{i}$ to $\tilde{\beta}=\beta_{j}$ as $\eta_{i j}$ )

$$
\left(\begin{array}{ccc}
\eta_{h h} & \eta_{h m} & \eta_{h \ell} \\
\eta_{m h} & \eta_{m m} & \eta_{m \ell} \\
\eta_{\ell h} & \eta_{\ell m} & \eta_{\ell \ell}
\end{array}\right)=\left(\begin{array}{ccc}
599 / 600 & 1 / 600 & 0 \\
1 / 4800 & 4798 / 4800 & 1 / 4800 \\
0 & 1 / 600 & 599 / 600
\end{array}\right)
$$

The Gini coefficient for the U.S. wealth data is 0.80 (Budría Rodríguez et al. (2002)) while the Gini coefficient in the stationary equilibrium of this model is also 0.80 .

The borrowing limit $\underline{a}$ is set so that the number of agents with negative value of wealth is in line with the data. In the U.S. data, $7.4 \%$ of households have strictly negative wealth and $2.5 \%$ have zero wealth (Budría Rodríguez et al. (2002)). I set $\underline{a}=-9.4$ so that the fraction of the agents with negative wealth is $9.8 \%$. Note that in the data there is a spike in the density function of wealth at exactly zero, while in the model "zero" is not a special number and there is no spike.

Figures 26 to 28 plot the population (measure) of agents with wealth level $a$, employment status $i \in\{e, u\}$, and $\tilde{\beta}=\beta_{j}$ where $j \in\{h, m, \ell\}, f^{i}(a ; j)$. As expected, the average wealth level is higher when the discount factor is larger. 


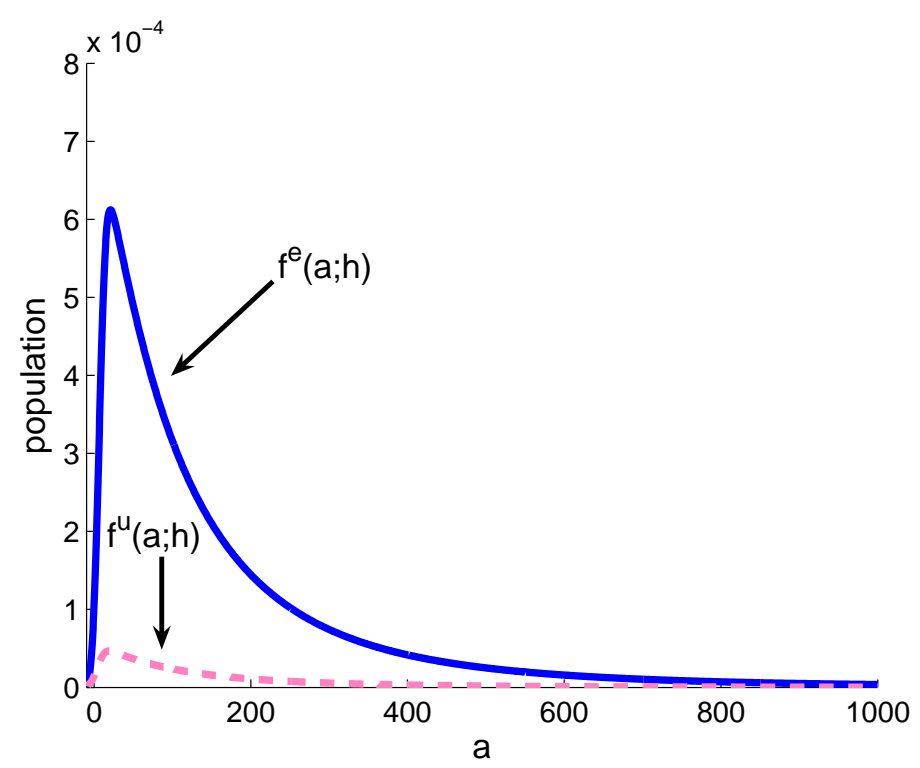

Figure 26: Wealth distribution for $\tilde{\beta}=\beta_{h}$ : stationary measure of employed consumers $\left(f^{e}(a ; h)\right)$ and unemployed consumers $\left(f^{u}(a ; h)\right)$

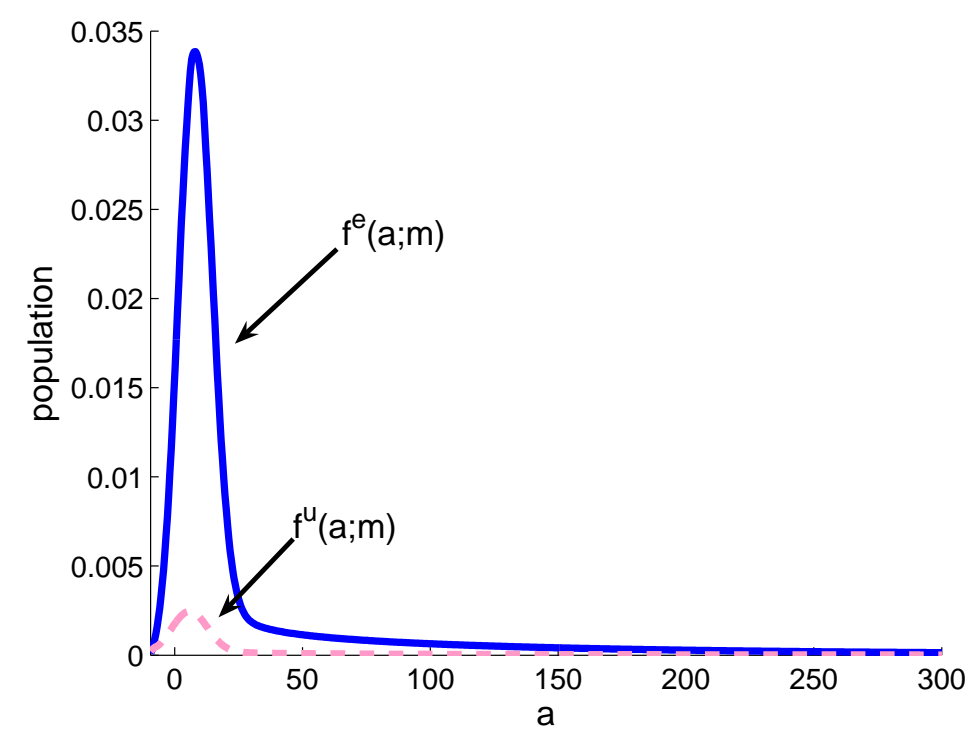

Figure 27: Wealth distribution for $\tilde{\beta}=\beta_{m}$ : stationary measure of employed consumers $\left(f^{e}(a ; m)\right)$ and unemployed consumers $\left(f^{u}(a ; m)\right)$ 




Figure 28: Wealth distribution for $\tilde{\beta}=\beta_{\ell}$ : stationary measure of employed consumers $\left(f^{e}(a ; \ell)\right)$ and unemployed consumers $\left(f^{u}(a ; \ell)\right)$ 


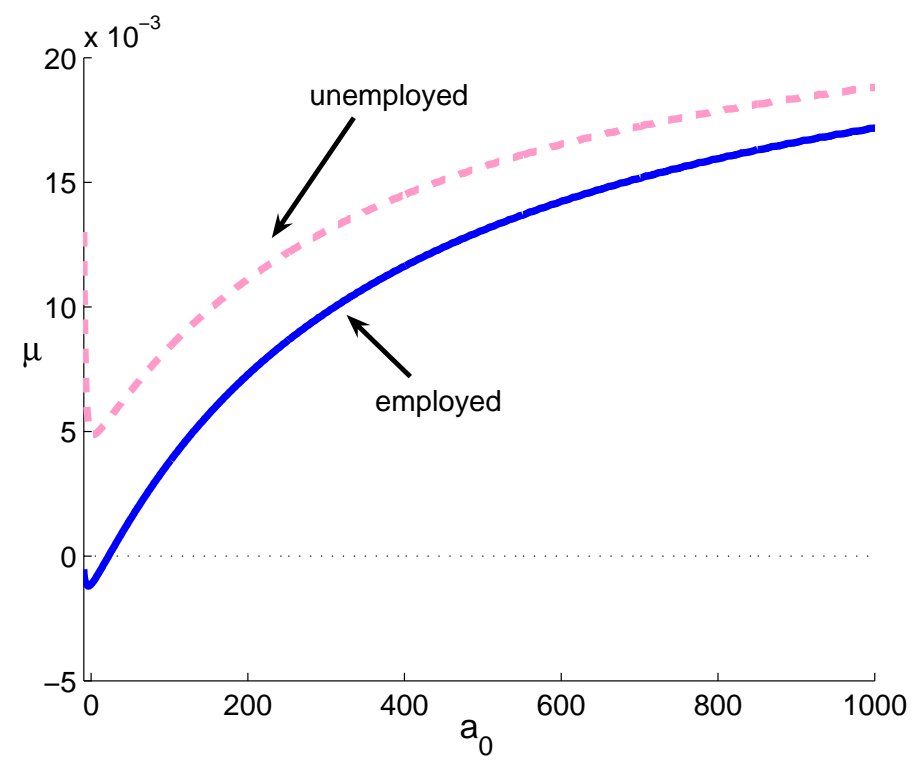

Figure 29: Welfare effects of the policy change: $\beta=\beta_{h}$

The experiments are identical to Section 2 (the experiments with tax only and the benefit only are omitted). Figures 29 to 31 plot the welfare effect $\mu$ for each level of $\tilde{\beta}$. All figures look similar to Figure 3 - the unemployed consumers benefit more and the benefit has a U-shaped relationship with the wealth level. 


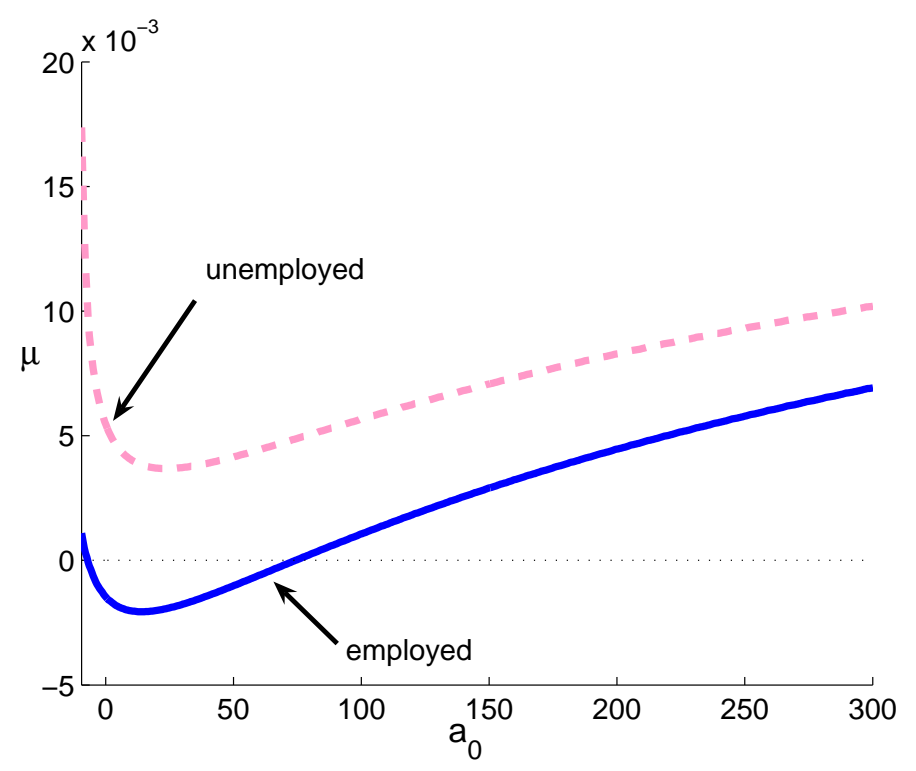

Figure 30: Welfare effects of the policy change: $\beta=\beta_{m}$

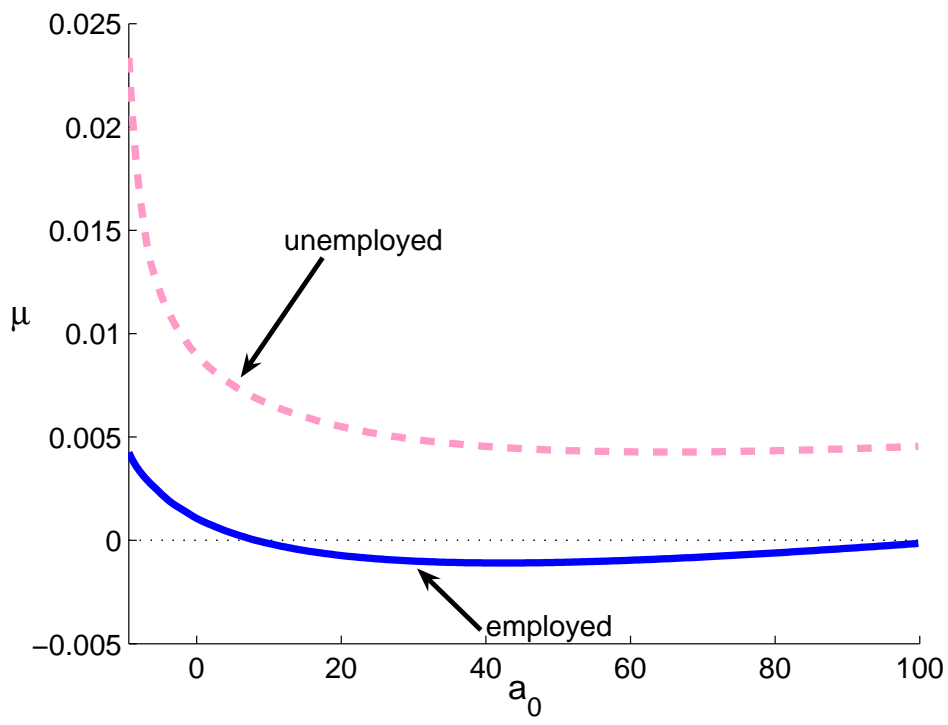

Figure 31: Welfare effects of the policy change: $\beta=\beta_{\ell}$ 


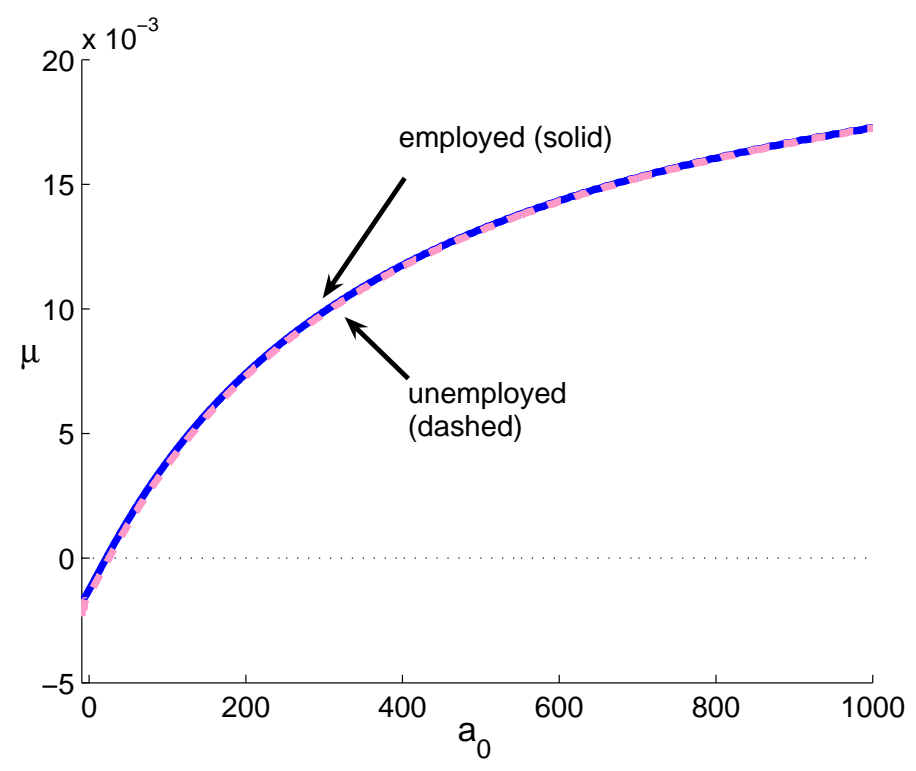

Figure 32: Welfare effects of the policy change: price effect, $\beta=\beta_{h}$

Figures 32 to 34 plot the price effect. They are similar to Figure 4. 


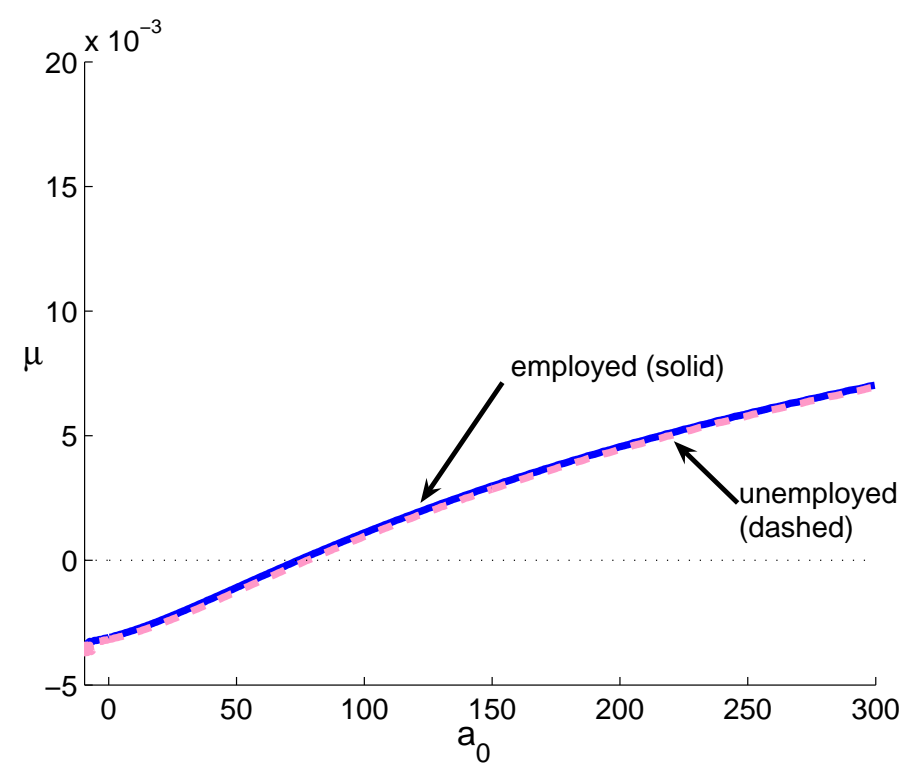

Figure 33: Welfare effects of the policy change: price effect, $\beta=\beta_{m}$

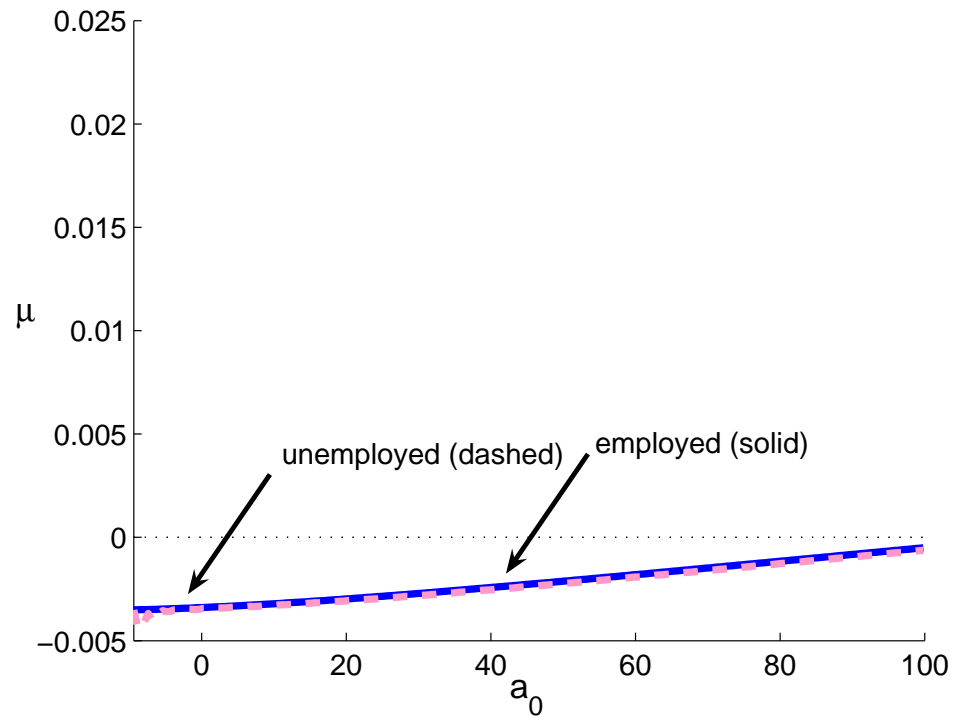

Figure 34: Welfare effects of the policy change: price effect, $\beta=\beta_{\ell}$ 


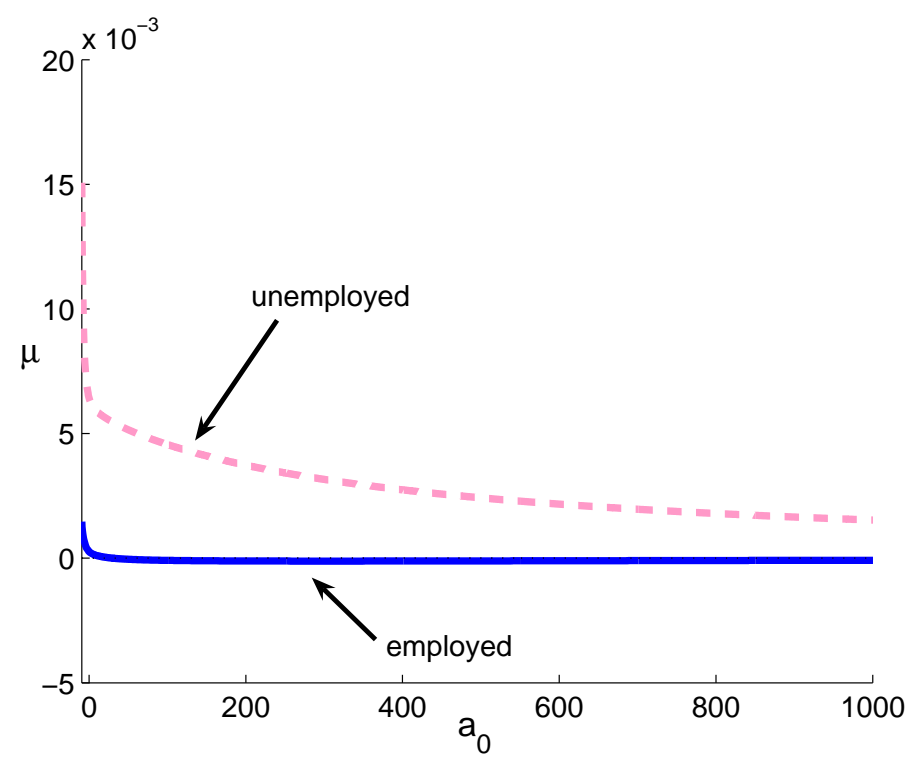

Figure 35: Welfare effects of the policy change: tax effect and benefit effect together, $\beta=\beta_{h}$

Figures 35 to 37 plot the outcome from the experiment that puts the tax effect and the benefit effect together. They are similar to Figure 7 . 


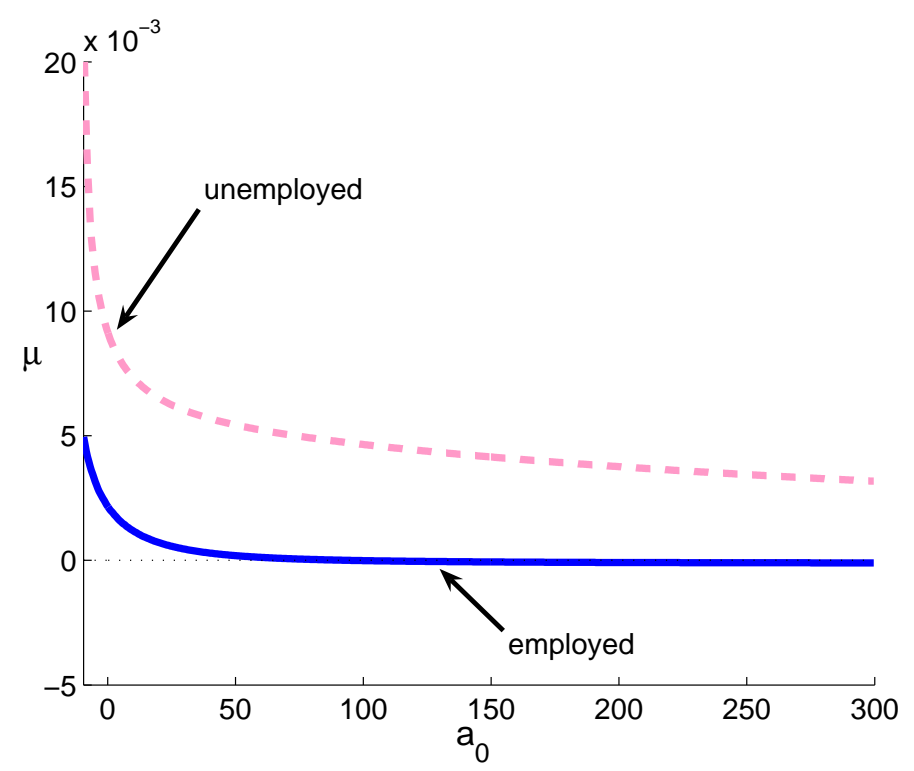

Figure 36: Welfare effects of the policy change: tax effect and benefit effect together, $\beta=\beta_{m}$

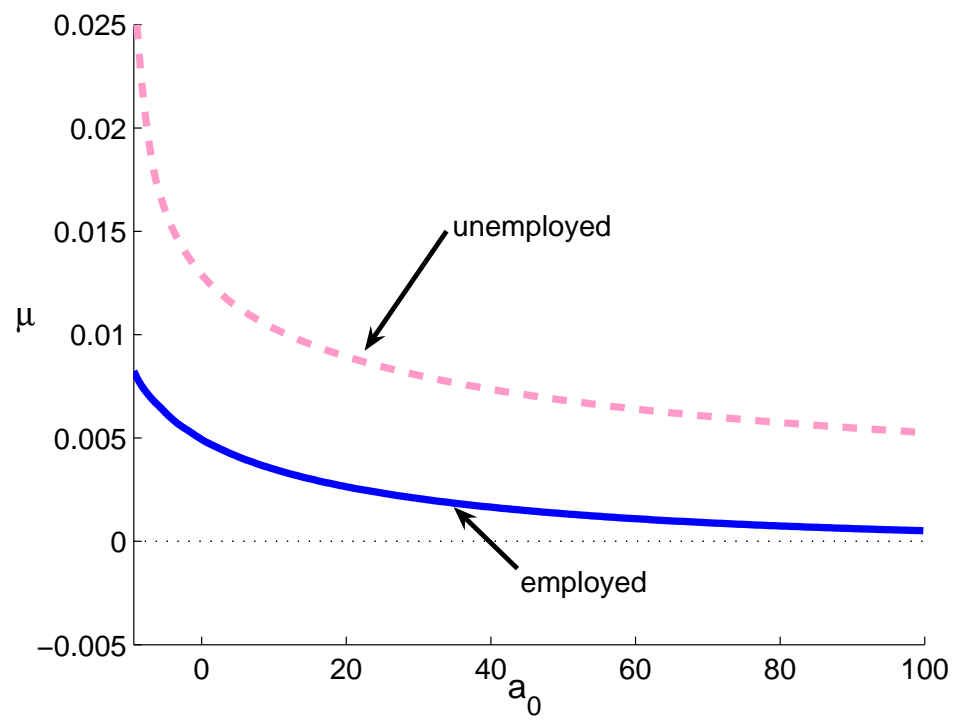

Figure 37: Welfare effects of the policy change: tax effect and benefit effect together, $\beta=\beta_{\ell}$ 


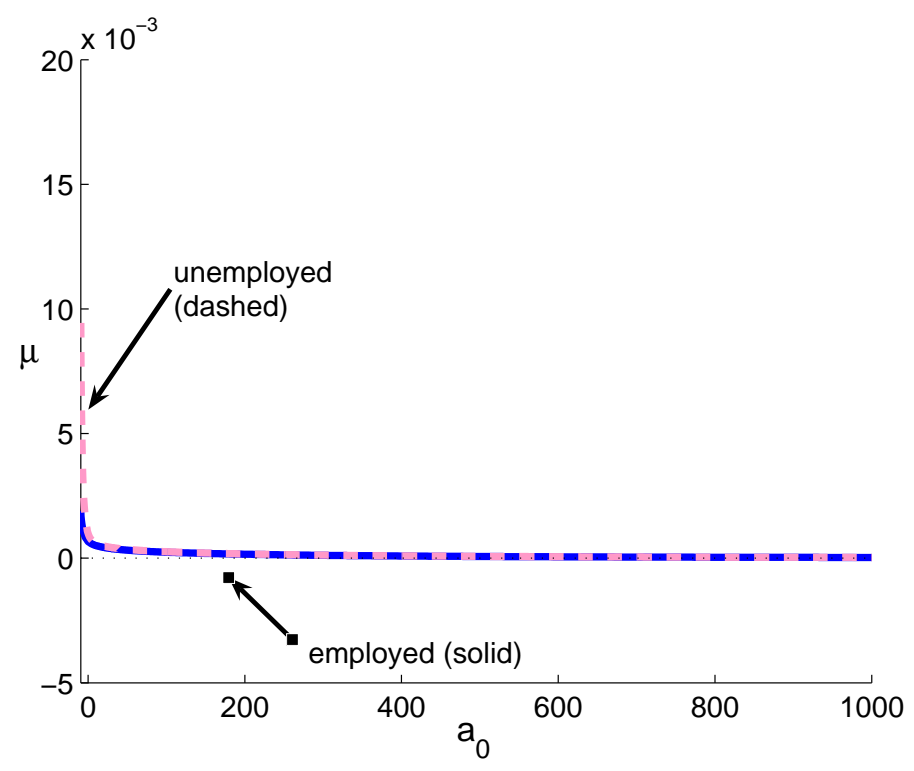

Figure 38: Welfare effects of the policy change: pure insurance effect, $\beta=\beta_{h}$

Figures 38 to 40 plot the pure insurance effect. Again, they are similar to Figure 8. 


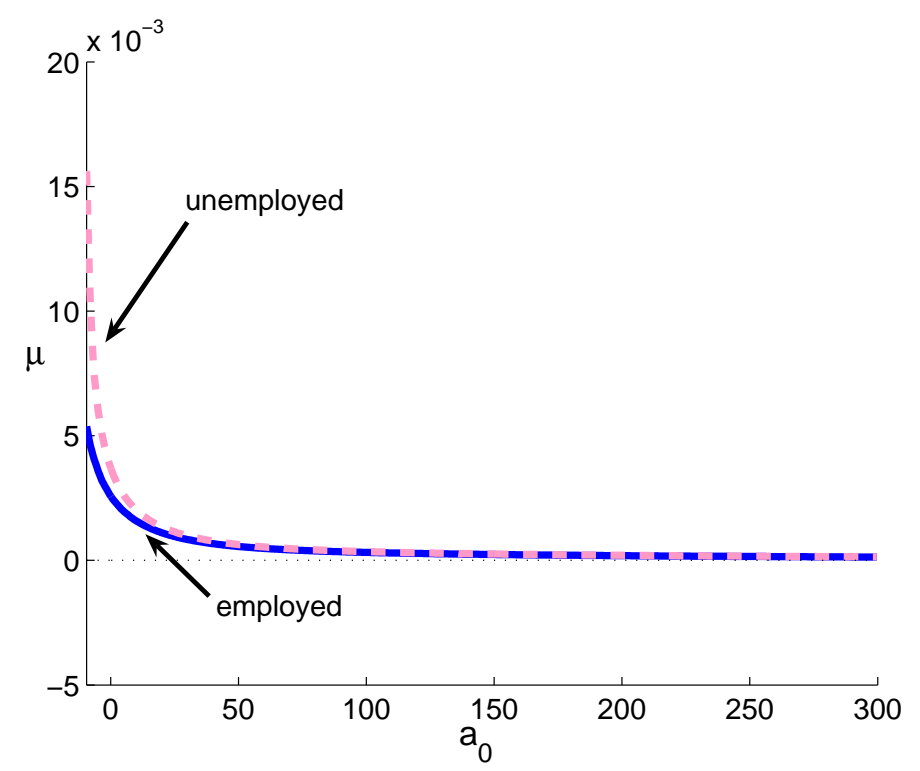

Figure 39: Welfare effects of the policy change: pure insurance effect, $\beta=\beta_{m}$

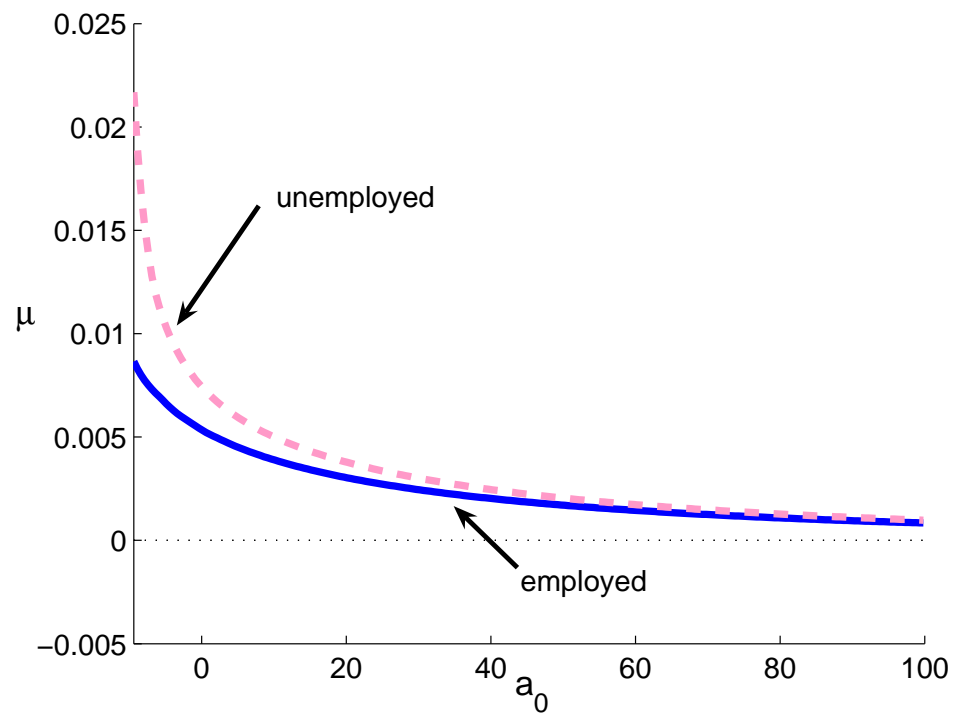

Figure 40: Welfare effects of the policy change: pure insurance effect, $\beta=\beta_{\ell}$ 


\section{B Moral hazard model with $\omega=8$}

This section conducts the same set of experiments as in Section 3. The model is the same as Section 3, except that the value of $\omega$ in (2) is set at $\omega=8$. The value of $\phi$ is adjusted to $\phi=0.415$ so that the steady state unemployment rate before the experiment becomes $7.1 \%$. The response of the unemployment to the increase in the UI benefit is much smaller than in Section 3: it goes up to $7.8 \%$. Figures 41 to 46 summarize the results. Figure 41 is the welfare effect of the full experiment, Figure 42 is the price effect, Figure 43 is the tax effect, Figure 44 is the benefit effect, Figure 45 is the tax effect and the benefit effect combined, and Figure 46 is the pure insurance effect. Overall, the welfare effect is higher than in Section 3: this is because the moral hazard effect is not as severe as in Section 3.

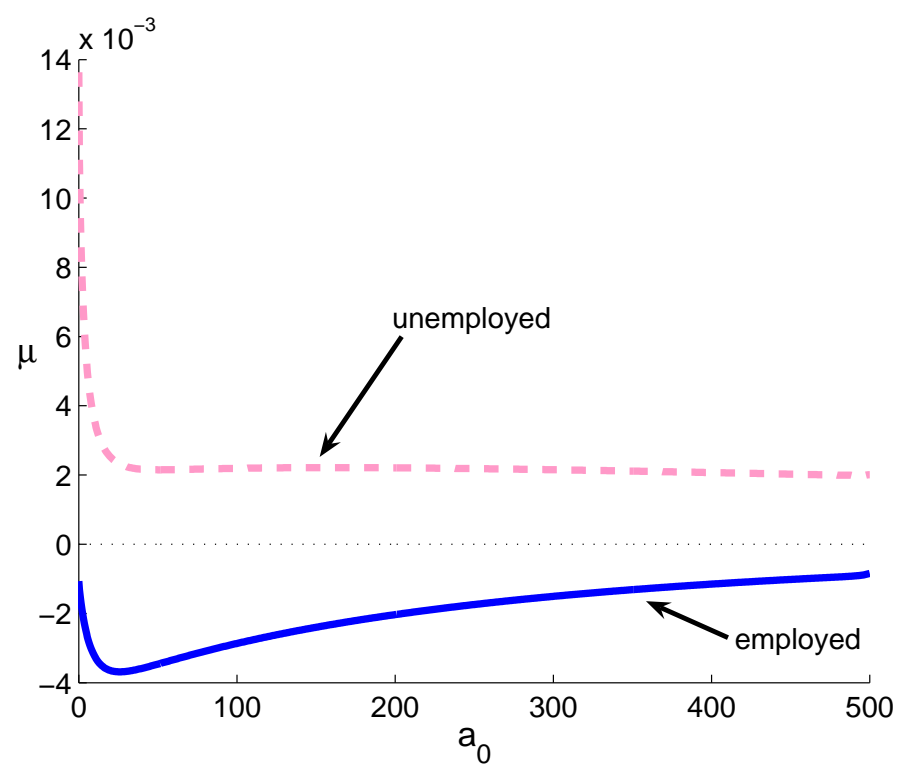

Figure 41: Welfare effects of the policy change 


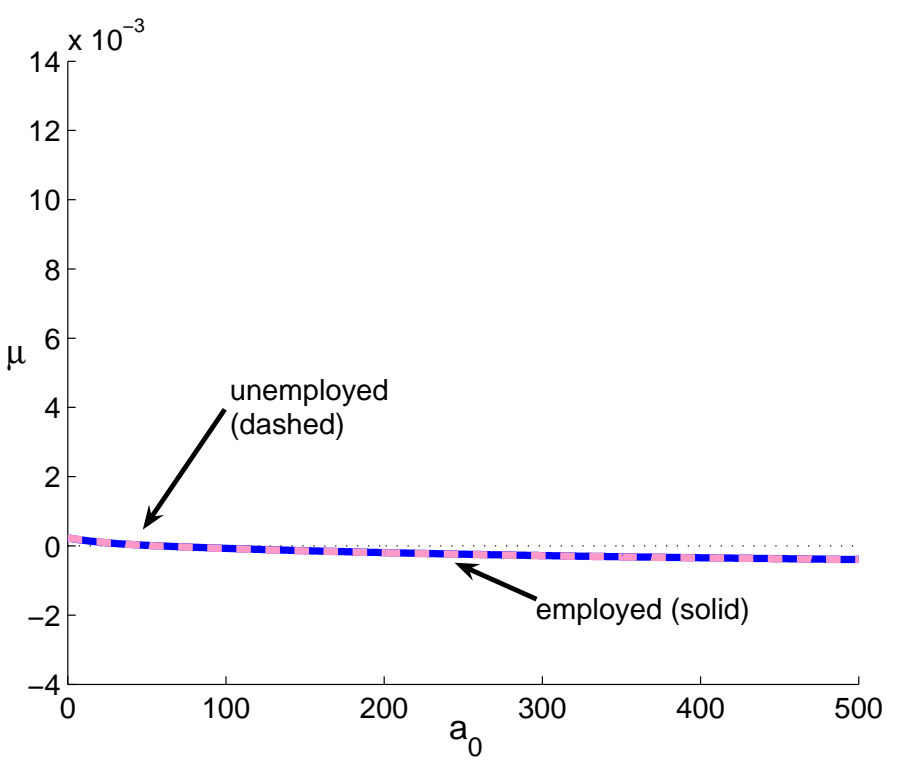

Figure 42: Welfare effects of the policy change: price effect

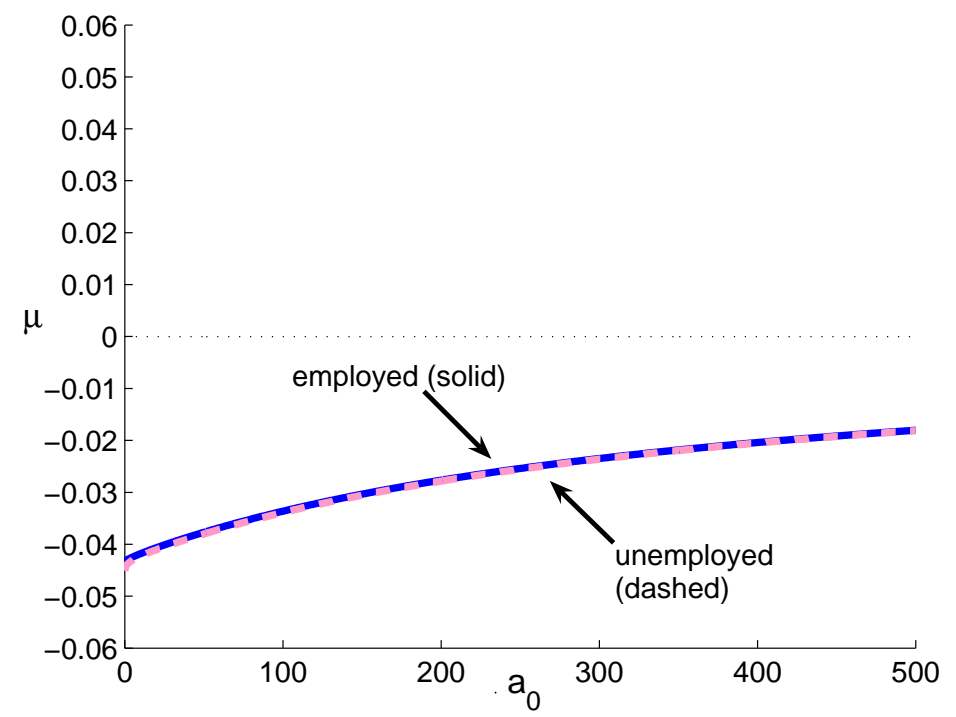

Figure 43: Welfare effects of the policy change: tax effect 


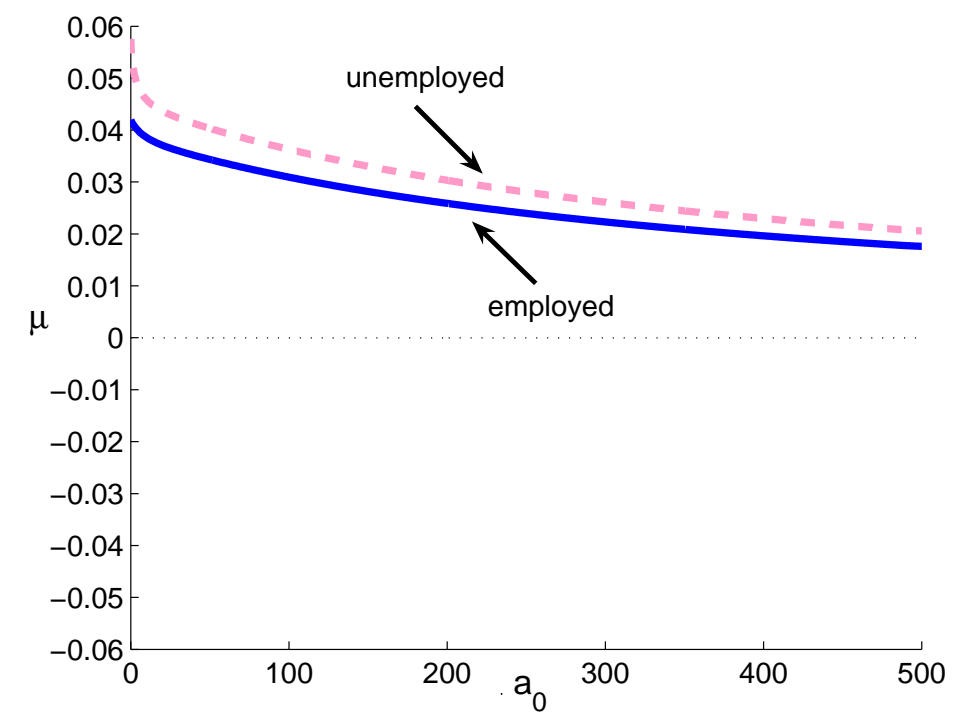

Figure 44: Welfare effects of the policy change: benefit effect

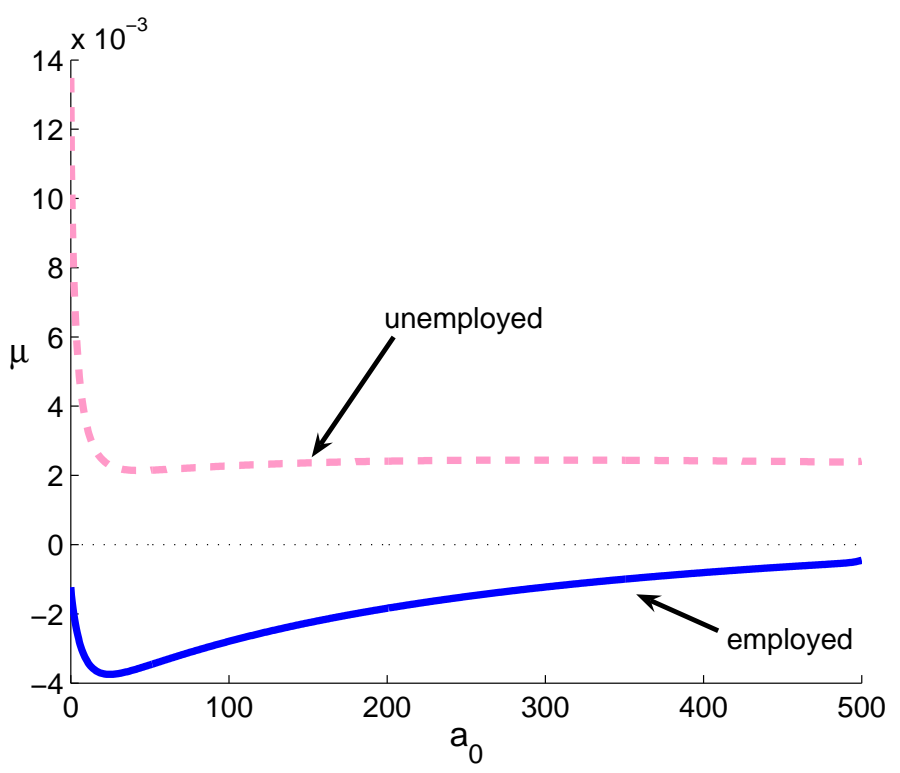

Figure 45: Welfare effects of the policy change: tax effect and benefit effect together 


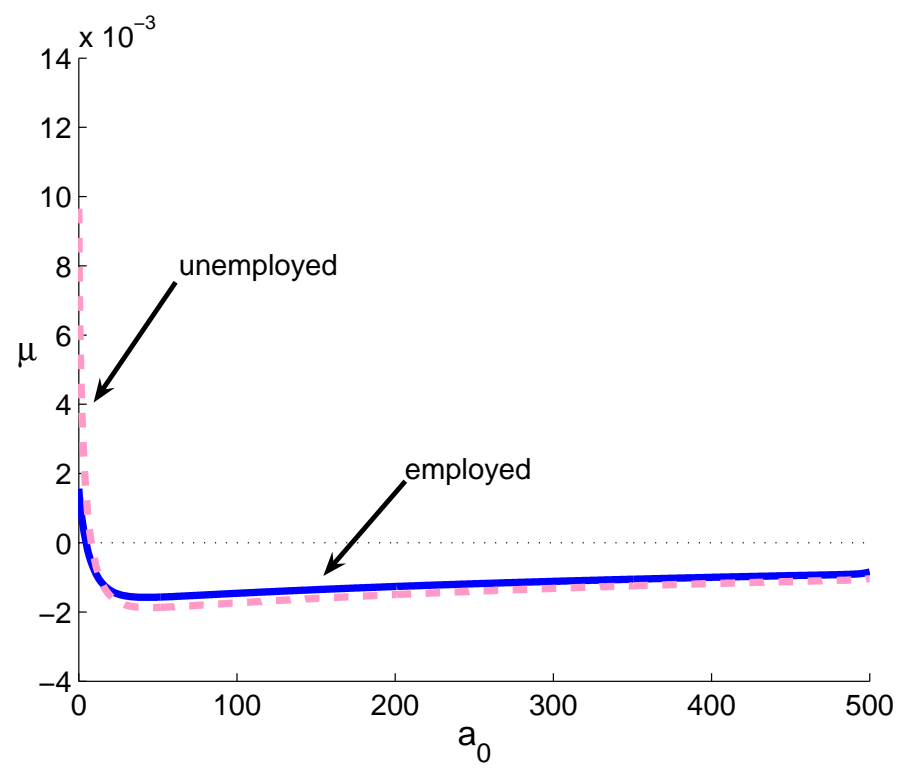

Figure 46: Welfare effects of the policy change: pure insurance effect 


\section{Matching model with linear utility}

In this section, I show that the optimal unemployment insurance (the notion of "optimality" is defined later)is strictly positive if and only if $\eta>\gamma$. The setting and the notations are exactly the same as in Section 4, except that the utility function of the consumer is linear:

$$
\mathbf{U}=E\left[\sum_{t=0}^{\infty} \beta^{t} c_{t}\right] .
$$

I follow the same steps as Pissarides (2000, Chs. 8 and 9) and compare the market equilibrium and the (constrained) social planner's optimal solution. The main difference from Pissarides (2000, Chs. 8 and 9) is that the model here is a discrete-time model.

Note that, with linear utility, the output per match is always set at $y \equiv\left(\tilde{k}^{*}\right)^{\alpha} \bar{h}^{1-\alpha}$ in both market equilibrium and social optimum, where $\tilde{k}^{*}$ satisfies

$$
\frac{1}{\beta}-1+\delta=\alpha\left(\tilde{k}^{*}\right)^{\alpha-1} \bar{h}^{1-\alpha} .
$$

I will consider the steady state, that is, the unemployment rate is given by a constant $u^{*}$ and the aggregate asset holding $A^{*}$ is equal to the aggregate capital $K^{*}=\left(1-u^{*}\right) \tilde{k}^{*}$ plus the discounted sum of the aggregate profit $p^{*}$. Thus, the question here can be formally stated as follows. "Suppose that the social planner's optimal solution yields the steady state with the unemployment rate $u^{*}$, the aggregate capital $K^{*}$, and the discounted sum of profit $p^{*}$. Then, what is the level of balanced-budget unemployment insurance benefit $b$ that can replicate the same outcome in the market equilibrium once the economy starts from the unemployment level $u^{*}$ and the consumer's asset level $A^{*}=K^{*}+p^{*}$ ?" I will denote this level of $b$ as $b^{*}$.

First, consider the market equilibrium. I will omit the time subscript since I will only look at the steady state. The Bellman equations for the consumers are:

$$
W=w-T+\beta[(1-\sigma) W+\sigma U]
$$

and

$$
U=b-T+\beta\left[\lambda_{w}(\theta) W+\left(1-\lambda_{w}(\theta)\right) U\right],
$$

where $T$ satisfies the balanced budget constraint $T=(1-u) b$. The Bellman equations for the firm are:

$$
V=-\xi+\beta\left[\lambda_{f}(\theta) J+\left(1-\lambda_{f}(\theta)\right) V\right]
$$

for a vacancy and

$$
J=y-w+\beta[(1-\sigma) J+\sigma V]
$$

for a matched job. The free entry condition is $V=0$ whenever $\theta>0$.

The wage is determined by the Nash bargaining solution:

$$
w=\arg \max _{w} \quad(W-U)^{\gamma}(J-V)^{1-\gamma}
$$


Following the same steps as Pissarides (2000, Ch. 8), the equilibrium value of $\theta$ is determined by the following equation:

$$
\mathcal{F}(\theta ; \eta, \gamma, b)=0
$$

where

$$
\mathcal{F}(\theta ; \eta, \gamma, b) \equiv(1-\gamma)(y-b)-\frac{1-\beta(1-\sigma)+\beta \gamma \theta^{1-\eta}}{\beta \theta^{-\eta}} \xi
$$

Note that $\mathcal{F}(\theta ; \eta, \gamma, b)$ is strictly decreasing in $\theta, \gamma$, and $b$.

Now consider the social planner's problem. The social planner maximizes the discounted sum of the aggregate output (minus the vacancy cost)

$$
\mathbf{O}=\sum_{t=0}^{\infty} \beta^{t}\left[y\left(1-u_{t}\right)-\xi \theta_{t} u_{t}\right]
$$

subject to the search friction

$$
u_{t+1}=\sigma\left(1-u_{t}\right)+\left(1-\lambda_{w}\left(\theta_{t}\right)\right) u_{t}
$$

for all $t$. Let the Lagrange multiplier for the time $t$ constraint be $\mu_{t}$. Then, the first order condition with respect to $\theta_{t}$ is

$$
-\beta^{t} \xi u_{t}+\mu_{t} u_{t}(1-\eta) \theta^{-\eta}=0
$$

and the first order condition with respect to $u_{t+1}$ is

$$
-\beta^{t+1}\left(y+\xi \theta_{t+1}\right)+\mu_{t}+\mu_{t+1}\left(\sigma-1+\theta_{t+1}^{1-\eta}\right)=0 .
$$

Combining these two, the steady state $\theta$ solves the following equation.

$$
\mathcal{G}(\theta ; \eta)=0
$$

where

$$
\mathcal{G}(\theta ; \eta) \equiv(1-\eta) y-\frac{1-\beta(1-\sigma)+\beta \eta \theta^{1-\eta}}{\beta \theta^{-\eta}} \xi .
$$

Note that $\mathcal{G}(\theta ; \eta)$ is strictly decreasing in $\theta$, so that there is a unique $\theta$ that satisfies (11) for a given $\eta$. Let $\Theta(\eta)$ be this unique solution of $\theta$.

Also note that once the time series of $\theta$ is determined, the time series of all the aggregate variables are pinned down (for both market equilibrium and social planner's solution). Then, the optimal unemployment benefit $b^{*}$ is the level of benefit $b$ where the solution $\Theta(\eta)$ to (11) is also a solution to $(9)$ for a given $(\eta, \gamma)$. Therefore, $b^{*}$ solves

$$
\mathcal{F}\left(\Theta(\eta) ; \eta, \gamma, b^{*}\right)=0
$$

for a given $(\eta, \gamma)$. Comparing (10) and (12) reveals that $b^{*}=0$ when $\gamma=\eta$ (Hosios condition). Since $\mathcal{F}(\theta ; \eta, \gamma, b)$ is strictly decreasing in both $\gamma$ and $b, b^{*}>0$ if and only if $\gamma<\eta$. 


\section{Matching model with $\gamma=0.5$}

This section conducts the same set of experiments as in Section 4. The model is the same as Section 4, except that the value of $\gamma$ in the Nash bargaining (7) is set at $\gamma=0.5$. As is discussed in footnote 19 and Appendix $\mathrm{C}$, a lower value of $\gamma$ for a given $\eta$ makes a high UI benefit more desirable with a linear model. This effect carries over to our model - with $\gamma=0.5$, the benefit from increasing the UI benefit tends to be larger.

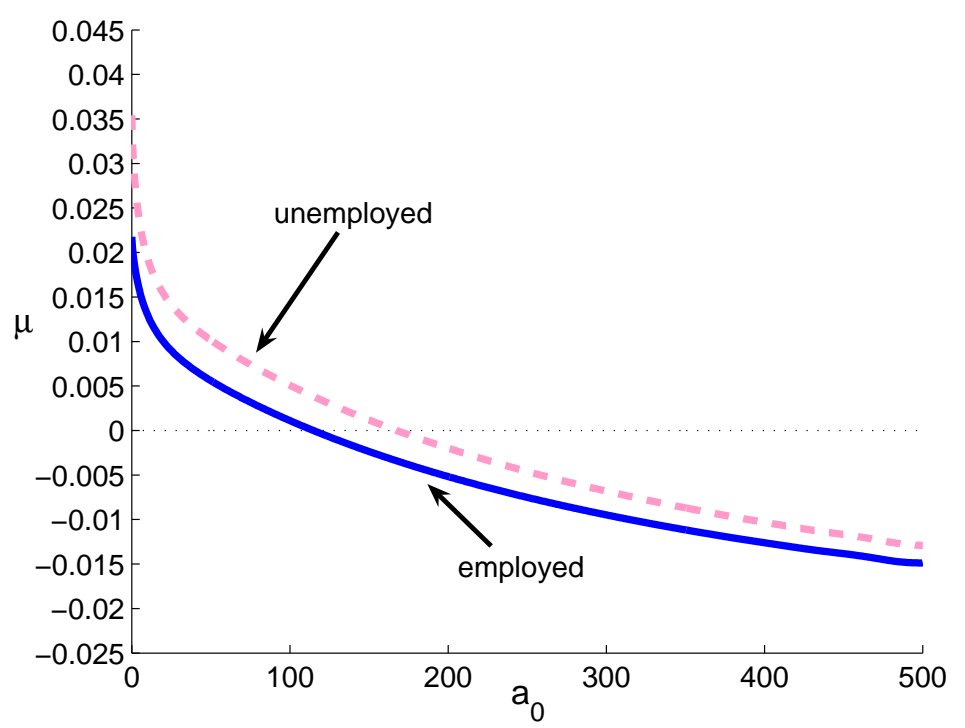

Figure 47: Welfare effects of the policy change

Figure 47 plots the welfare effects from the full experiment. Compared to Figure 18, the welfare effect is larger for most of the consumers. In fact, $95 \%$ of the consumers experience a positive gain $(0.03 \%$ in Section 4.2 .1$)$. Figures 48 to 53 plot the decomposition similar to Section 4. 


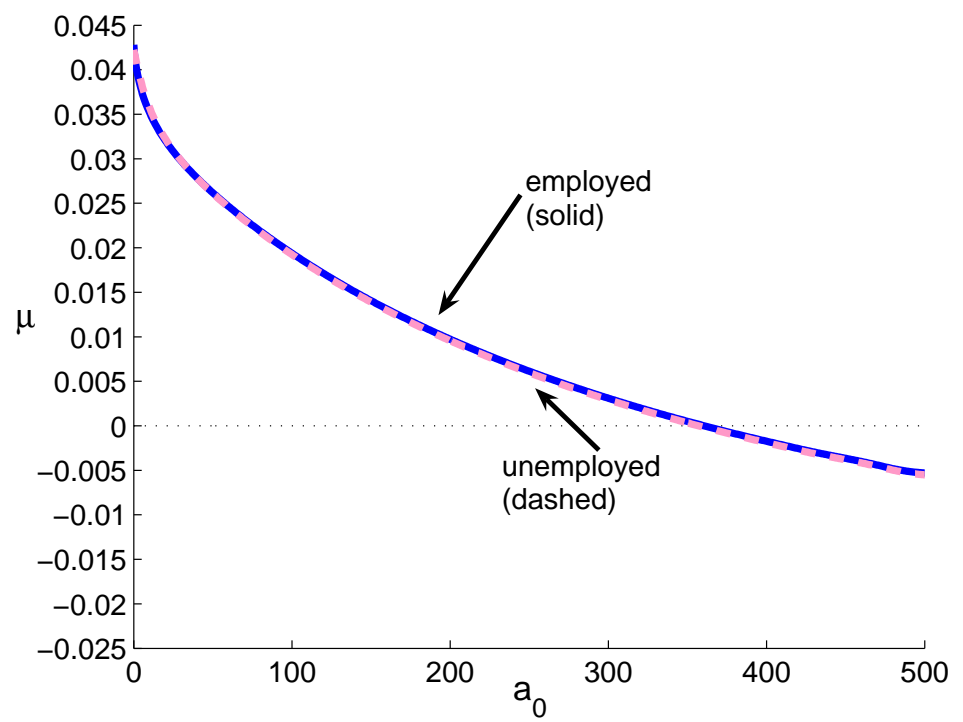

Figure 48: Welfare effects of the policy change: price effect



Figure 49: Welfare effects of the policy change: matching effect 


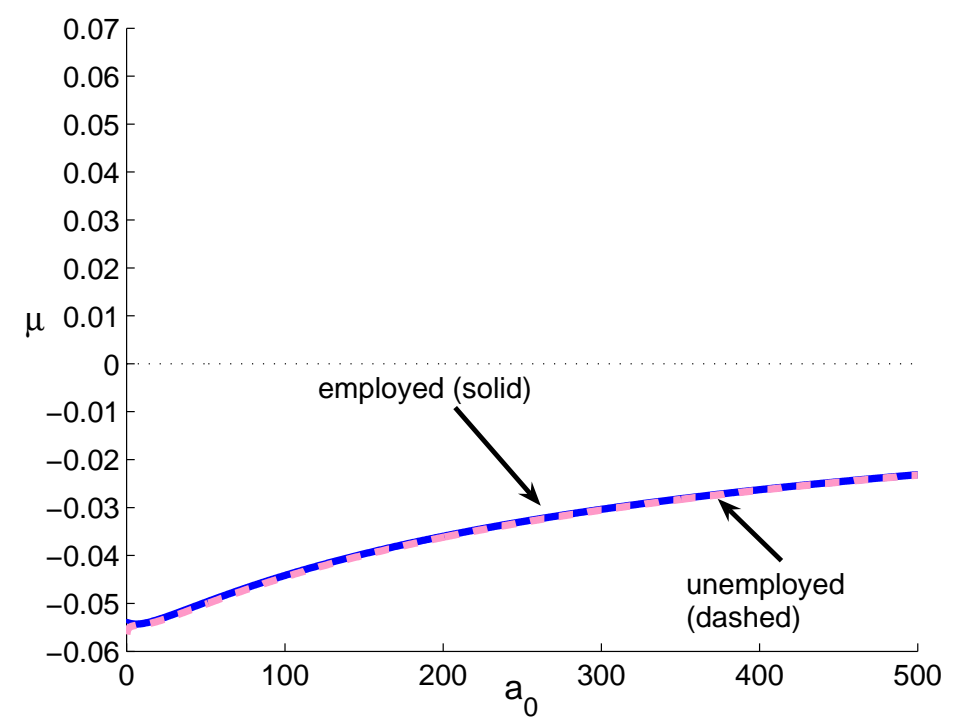

Figure 50: Welfare effects of the policy change: tax effect

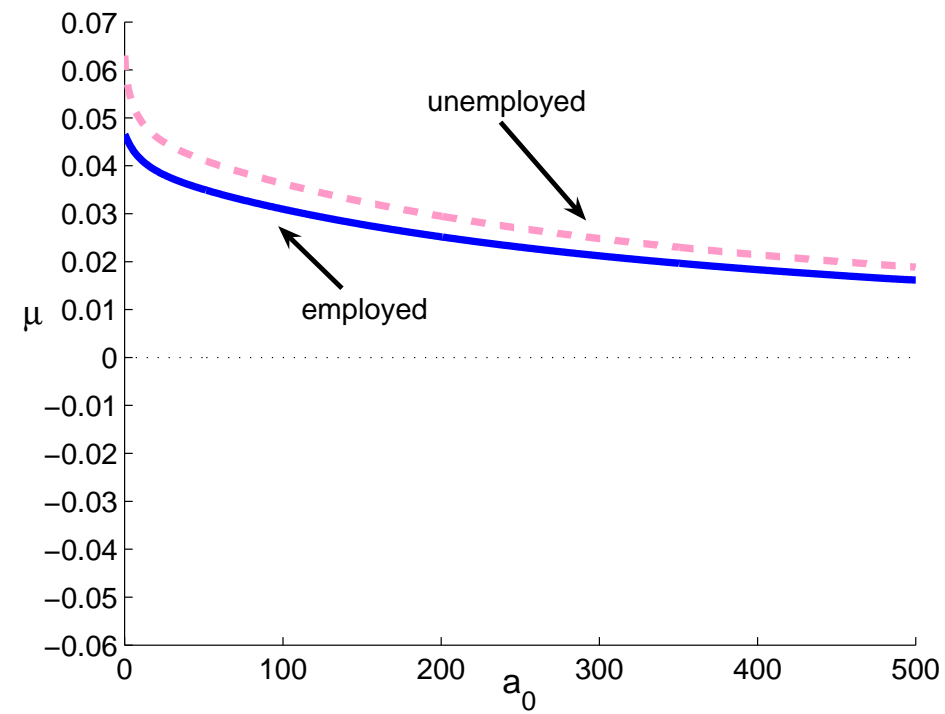

Figure 51: Welfare effects of the policy change: benefit effect 


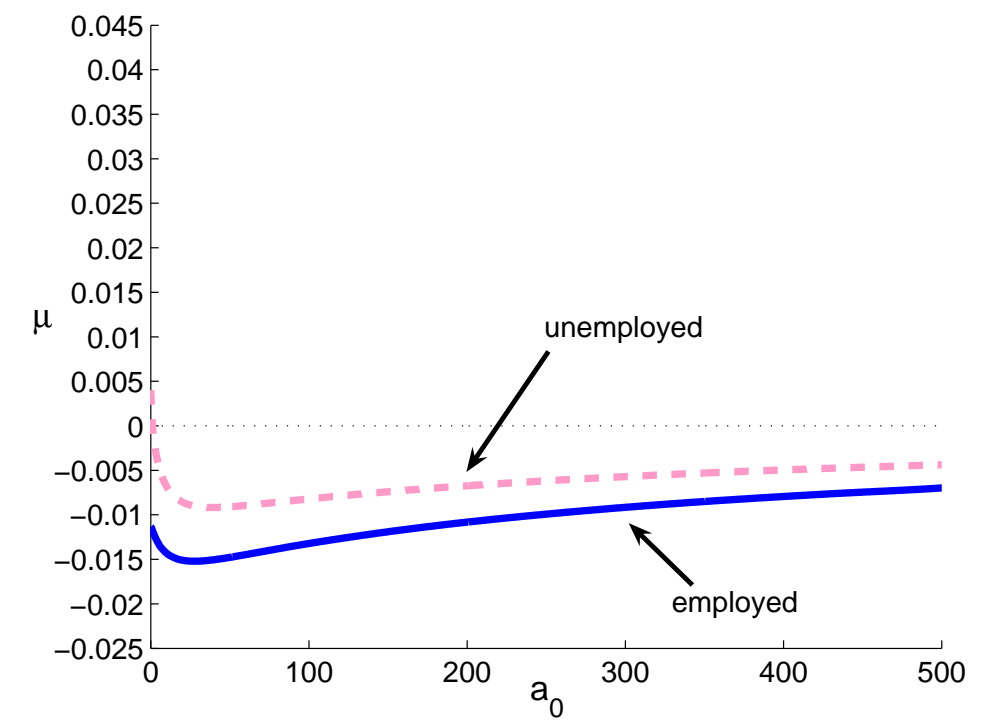

Figure 52: Welfare effects of the policy change: tax effect and benefit effect together

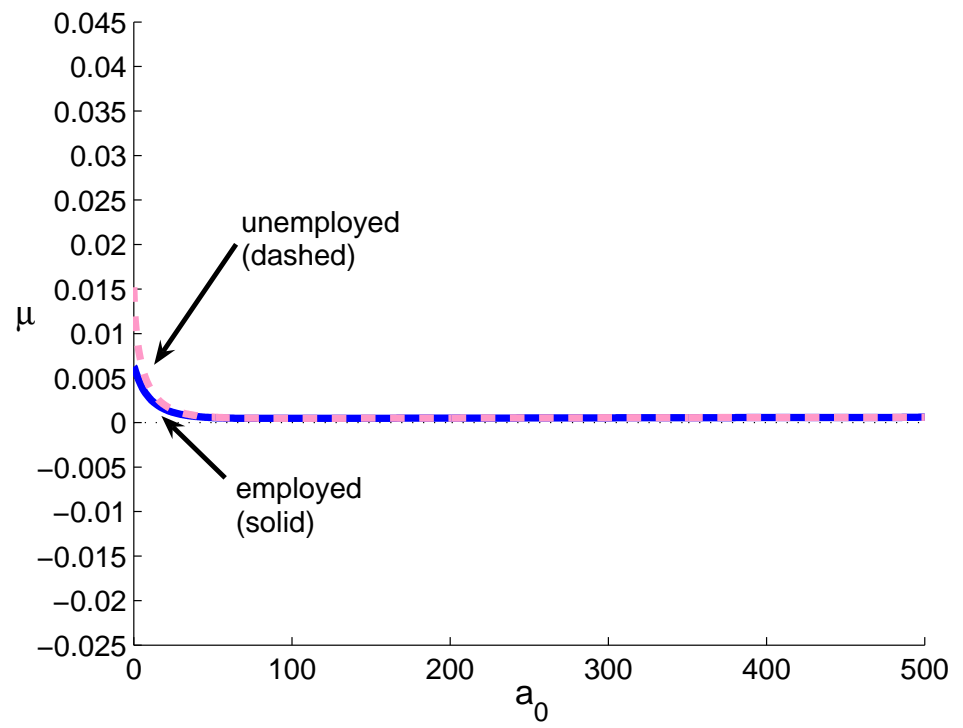

Figure 53: Welfare effects of the policy change: pure insurance effect 